\title{
Venationes y poder en la Roma imperial: poesía panegírica y crítica
}

\section{Venationes and Power in the Roman Empire: Poetry between Panegyric and Criticism}

\author{
Vicente Flores Militello \\ https://orcid.org/0000-0002-2935-2849 \\ Instituto de Investigaciones Filológicas, Universidad Nacional Autónoma de México, México \\ vicente.fm@comunidad.unam.mx
}

RESUMEN: El presente artículo expone a través de ejemplos selectos el papel que el tema de la venatio jugó en la poesía de época imperial dentro de un discurso panegírico o en la crítica satírica. Tras una definición y resumen histórico breve de las venationes, entendidas como espectáculos oficiales de lucha y caza de animales salvajes en la arena, y la diferenciación entre poesía venatoria y poesía cinegética en general, se aclara el peso político que tales espectáculos tienen. El objetivo es, así, exponer cómo diversos autores tratan el fenómeno de manera positiva o negativa y demostrar cómo la poesía que tematiza la venatio se afirma, en parte a través de conceptos filosóficos, como un medio literario apto para tal fin. Centrales serán pasajes de la séptima égloga de Calpurnio Sículo, del Liber spectaculorum y del liber primus de los epigramas de Marcial, la Silva 2, 5 de Estacio y pasajes de las Sátiras 4 y 10 de Juvenal.

PAlabras Clave: venatio, panegírico, sátira, magnanimitas, clementia, representación imperial

ABSTRACT: This article presents through selected passages the role played in Imperial Poetry by the theme venatio within a panegyrical or satirical discourse. It will offer a brief definition as well as a summary of the historical development of the venationes, considered as official spectacles in the arena in which wild animals fought with each other or were chased. The difference between venatio and cynegetic in poetry will also be discussed. Hence, the political importance of these spectacles will be clarified. The aim is thus an exposition of how different authors deal with this phenomenon in a positive or negative way, and show how poetry that thematizes the venatio partly through philosophical concepts proves itself as a suitable medium for this kind of representation. Some passages from Calpurnius Siculus' seventh ecloga, and Martial's Liber spectaculo- 
rum will play a central role, as well as some epigrams from his liber primus, Statius' Silva 2, 5, and finally, some passage from Juvenal's fourth and tenth Saturae.

Keywords: venatio, Panegyric, Satire, magnanimitas, clementia, Imperial Representation

ReCiBIDO: 03/03/2020 • ACEPTADO: 28/04/2020 • VeRSión FinAL: 23/06/2020

En un célebre pasaje de la Sátira, 10, Juvenal deplora la inercia política y social de la Roma imperial. El pueblo de Roma, metonímicamente la turba Remi (73), fuente primigenia del derecho y la legitimidad, no distingue ya, inerte, entre el bien y el mal, se contenta con un superficial bienestar inmediato. La fórmula para tenerlo satisfecho es simple, y el poder la conoce bien: pan y circo (panem et circenses). ${ }^{1}$

Juvenal se concentra, para este pasaje, en el reinado de Tiberio y, como es típico en este autor, presenta un pasado remoto republicano idealizado, que fue decayendo a lo largo del imperio hasta llegar a un atemporal 'presente', brutal, en el que no hay más esperanza. Resulta lógico considerar que el garantizar una subsistencia material en forma de pan y un distractor social en forma de espectáculos del circo, no son una fórmula únicamente de la época imperial romana o incluso republicana: representan mutatis mutandis una táctica habitual inherente a gran parte de las sociedades en mayor o menor grado desarrolladas, y que la locución juvenaliana se haya vuelto proverbial es un indicador de cuánto comprendemos esta problemática aún hoy.

La historia de los juegos circenses está íntimamente ligada a la representación del poder, y el papel que estos desempeñan en el mundo romano es fundamental para entender un discurso de panegírico oficial que, particularmente en el imperio, encontró una expresión fortísima en distintas obras artísticas y literarias hasta bien entrada la época tardo antigua.

En el presente artículo me concentraré en un aspecto particular de los juegos circenses, las venationes (cacerías de animales en la arena organizadas oficialmente, esto es por el emperador), y en cómo son representadas en la poesía latina de época imperial con fines panegíricos (es decir, que demuestran y justifican el poder imperial), o, inversamente, de crítica.

\footnotetext{
${ }^{1}$ Juv., 10, 78b-81a: qui dabat olim / imperium, fasces, legiones, omnia, nunc se / continet atque duas tantum res anxius optat, / panem et circenses. Frontón, más o menos en la misma época de Juvenal, se expresa en términos similares sobre el emperador Trajano en un pasaje de los principia historiae (Front., Epist., 2, 18): no se le escapaba el poder que el circi aut harenae artificium tenía para satisfacer a las masas, pues sabía que el populus Romanus se domaba (teneri) fácilmente con dos elementos: annona et spectaculis.

${ }^{2}$ Cf. Uden 2015, p. 12.
} 
A partir de esto resultará evidente que el fenómeno de las venationes no solo gozó entre el público de un éxito inmenso, ${ }^{3}$ y que por ende el poder político sacó gran provecho de él; sino que la poesía con tema venatorio fue un medio literario muy apto para contribuir positiva o negativamente a tal fin.

\section{DEFINICIÓN}

Con el término venatio se puede entender una cacería de animales, primariamente en la naturaleza, ya sea por necesidad, deporte o placer. ${ }^{4}$ También, y este es el sentido más frecuente sobre todo a partir de la época tardorrepublicana ${ }^{5}$ y en el que quisiera concentrarme en el presente artículo, el término se refiere específicamente a las "cacerías" organizadas en la arena como espectáculo masivo con el fin de divertir y entretener al público (véanse términos clave como ludi, munus, spectaculum, cada uno indica particularidades de eventos festivos). ${ }^{6}$

Ahora bien, es casi natural preguntarse quién organizaba tales venationes, por qué y dónde. El organizador es un hombre político que desempeña una magistratura oficial relevante (un pretor o un cónsul, más adelante, principalmente el emperador). El motivo es celebrar la toma de posesión de algún

${ }^{3}$ Naturalmente, la bibliografía sobre la popularidad y la perduración de las venationes y otros ludi circenses es extensa, pues este es un fenómeno que no ha pasado desapercibido. Entre los estudios más sobresalientes destacan las respectivas monografías de Puk 2014 y de Dunbabin 2016. Ellos se concentran en el perdurar de los espectáculos circenses históricamente y en su representación artística hasta al menos finales del s. vI. Sobre el desarrollo histórico de la venatio destacan en las publicaciones de las últimas décadas el capítulo de Epplett 2014, pp. 505-519; y de Rea 2001, pp. 245-275.

${ }^{4}$ Cf. Cic., Sen., 16, 56, referido a uno de los placeres de la vida rústica, o Caes., B. Gall., $4,1,8$, relativo a las formas de alimentación de los Suebi. Como se puede ver, venatio es una forma sustantivada del verbo venari, que se usa ya en Plauto para significar "cazar" (Plaut., Capt., 184) o "ir a cazar" (Plaut., Men., 835). Como acción en sí, la caza no está obviamente

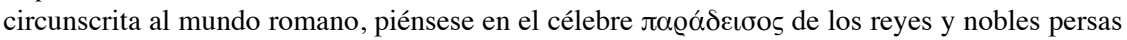
(cf. infra n. 12), un espacio cerrado, de medianas o grandes dimensiones, con abundancia de plantas y animales para cazar. Aymard 1951 ofrece un estudio aún actual en torno al desarrollo y la connotación ética de formación y 'virtud' que en Roma se daba a tal actividad (sobre todo en época republicana e imperial).

${ }^{5}$ Es frecuente su aparición a partir de Cicerón y Varrón.

${ }^{6}$ Con ludi se entienden los juegos públicos en general ofrecidos al pueblo de manera oficial y con carácter religioso/político. Se pueden dividir en ludi circenses (p. e., las carreras de caballos y las venationes) y ludi scaenici (diferentes representaciones teatrales y/o musicales). Por munus se entienden los espectáculos públicos (por lo común de gladiadores, aunque a veces también en compañía de venationes) que organizaban usualmente magistrados y ediles para agradecer al pueblo por el cargo al que habían sido elegidos. Por spectaculum, se entiende el evento en sí que se desarrolla en la arena (desde juegos escénicos, hasta naumaquias, gladiadores, venationes, condenas ad bestias, etc.), aunque también indica la estructura del teatro o del anfiteatro en sí. Cf. Dunbabin 2016, pp. 4-8. 
cargo, en el caso de los magistrados, o algún triunfo militar. El lugar por antonomasia es sin duda Roma, aunque evidentemente es un fenómeno que, con el tiempo, se llevó a cabo en diferentes ciudades a lo largo y ancho del imperio romano. El sitio particular donde las venationes se realizaban era la arena (harena), un espacio por lo general elíptico cubierto, precisamente, de arena, que formaba el centro de construcciones como anfiteatros o circos (de madera, después de piedra). En Roma, la urbe por antonomasia, esto ocurría sobre todo en el espacio que se usaba ya desde tiempos monárquicos para distintos tipos de ludi, como carreras de caballos o peleas de gladiadores: ${ }^{7}$ lo que después se llamaría Circo Máximo. A partir del año 80 d. C., dichos eventos se realizaron en el gran Anfiteatro Flavio, que hoy se conoce con el nombre medieval de "Coliseo".

En líneas generales se podría decir que las venationes tienen la siguiente particularidad: en ellas, diversos animales salvajes luchan entre sí o también pueden ser cazados, o más bien instigados, por "cazadores" profesionales (venatores o bestiarii). Los animales preferidos para este tipo de actividades eran principalmente los grandes felinos del norte de África (ferae o bestiae Africanae) o de Asia Menor, así como osos, venados y jabalíes. La recolección, mantenimiento y transporte de estas bestias era una actividad lucrativa, aunque estaba ligada también a un costo muy elevado y a una logística que implicaba varios niveles administrativos. ${ }^{8}$ Esto explica por qué por lo general los animales exhibidos en la venatio no siempre estaban destinados a morir en la arena, sino que era frecuente su reutilización (de aquí que se hable de "instigar" o "azuzar" más que de "cazar"9 o incluso solo de exhibirlos), o por qué su muerte - accidental o provocada - tenía un peso particular. Esto muestra que la organización exitosa de una venatio traía un enorme prestigio al responsable de ella. Esta es una cuestión de peso para medir la popularidad política, sobre todo en época republicana, o para pro-

${ }^{7}$ Liv., 1, 35, 8-9.

${ }^{8}$ Cf. Rea 2001, en especial pp. 249-250. Sobre el papel que en época republicana jugaba el gobernador de una provincia para abastecer de animales salvajes de la región gobernada a quien quisiera organizar una venatio en Roma, en el caso de Cicerón en Cilicia y cómo (no) ayudó a conseguir en los años 51-50 a. C. varias panteras para M. Celio Rufo, edil del año 50 a. C., cf. Cic., Fam., 2, 11, 2; 8, 2, 2; 8, 4, 5; 8, 9, 3; 8, 8, 10; Att., 5, 21, 5; 6, 1, 2.

${ }^{9}$ En autores griegos que escriben acerca del mundo romano, sobre todo Dion Casio, quien más menciona esta actividad, la terminología se adapta al sentido particular con diferentes perí-

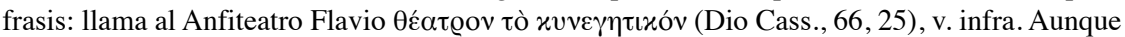

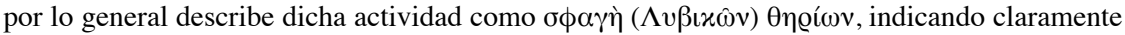

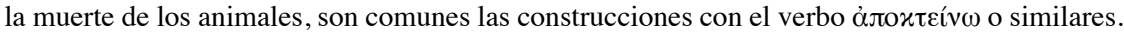

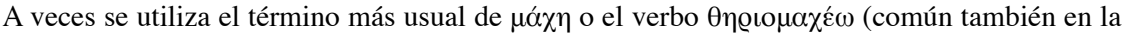

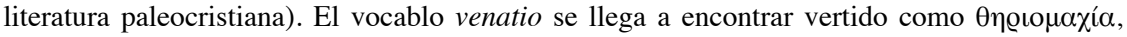
considerada una actividad típicamente romana (Strab., 2, 5, 33); Marco Aurelio habla sobre los

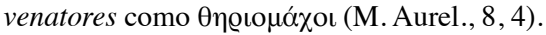


mocionar, parafraseando a Epplett, ${ }^{10}$ la influencia política que Roma (en la persona de un magistrado primero; del emperador, después) ejerce a través de sus expansiones y conquistas militares; al mismo tiempo como símbolo del dominio del emperador sobre la naturaleza misma: de aquí el interés en recolectar animales exóticos como elefantes, tigres de bengala o jirafas; obligar a combates en ambientes adversos a los naturales (como focas contra osos); o ser testigos de la "espontánea" sumisión de una bestia salvaje, un león, ante la "magnanimidad" del emperador.

Este elemento político es la clave, en mi opinión, para entender la importancia de la venatio y de los espectáculos circenses en general en el mundo romano, y en particular del rol panegírico que la poesía que la tematizó jugó en el discurso imperial.

Para el lector actual resulta una actividad sin duda cruel y poco apreciable, sin embargo el público antiguo no pensaba igual, sino que, llevado por el entusiasmo colectivo, la consideró un tema apto y provechoso para la literatura y las artes plásticas, como muestran los pasajes que mencionaré a continuación y numerosísimos mosaicos de villas aristocráticas a lo largo y ancho de las costas mediterráneas. La representación y tematización de la cacería, en especial de las venationes en la arena, sirve para manifestar el peso político y social de un determinado individuo: el organizador y patrocinador de tales actividades. Si los mosaicos remiten a organizadores de diferentes localidades, como Katherine Dunbabin ha demostrado convincentemente con base en diversos mosaicos del norte de África y del cercano Oriente, ${ }^{11}$ la literatura remite a una sola figura central: el emperador en Roma.

A continuación, me concentraré en el papel que la poesía jugó para la figura imperial. Llama la atención que solo a partir del imperio la venatio se volvió un tema recurrente en la literatura en verso, y tuvo un claro objetivo panegírico.

\section{ORÍGENES Y PESO POLÍTICO}

Los orígenes de la organización de cacerías como actividad social no se pueden buscar, naturalmente, en el mundo romano, porque son una actividad intrínseca de las culturas antiguas, en particular del mundo mediterráneo y

\footnotetext{
${ }^{10}$ Epplett 2014, p. 509. Él habla en particular de un doble valor político de las venationes: ve en ellas una "wider variety of propaganda functions", por un lado, la 'propaganda' de los triunfos militares (sobre todo en época republicana, pero también en época imperial); por el otro (y aquí especialmente en la época imperial), como símbolo del control del emperador sobre el mundo natural.

${ }^{11}$ Cf. Dunbabin 1978, 1999 y 2016.
} 


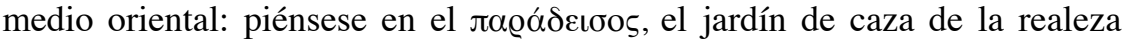
persa, por ejemplo. ${ }^{12}$

Por otro lado, la exhibición de animales salvajes (y amaestrados) como espectáculo para el pueblo, como parte de una estrategia política para mostrar poder, es clara ya en la Atenas del s. IV a. C. con los costosos espectáculos con leones y osos amaestrados que lamenta Isócrates en su Antidosis, ${ }^{13}$ o la procesión de animales exóticos en Alejandría de Egipto, organizada por Ptolomeo II en 275/274 a. C. ${ }^{14}$ En Roma, Plauto menciona el uso de animales africanos para celebrar la pompa en los ludi aediles. ${ }^{15}$

Sin embargo, el primer documento sobre la organización de espectáculos de "cacerías", y no meras pompae, lo encontramos en Tito Livio, referido al año 186 a. C.: Marco Fulvio Nobilior, cónsul ese año, organizó, tras su triunfo sobre Etolia, ingentes ludi en Roma. Entre los espectáculos que Livio destaca están el primer athletarum certamen de Roma y una venatio leonum et pantherarum. ${ }^{16}$

Como se puede observar, esta es una estrategia de agasajo al pueblo y demostración de poder con fines de prestigio político. Tal estrategia tendió a agudizarse hacia finales de la República. Basta considerar, como señala Chris Epplett, ${ }^{17}$ el testimonio de Plinio el Viejo acerca del creciente número de bestias (sobre todo felinos e incluso elefantes) en el último siglo a. C., desde Craso y Escévola (104 a. C.) hasta Pompeyo (55 a. C.) y César (46 a. C.). ${ }^{18}$ La primera evidencia arqueológica de la representación de las venationes con fines, podríamos decir, promocionales, proviene de esta época: el denario de Livineyo Régulo del 43/42 a. C. ${ }^{19}$ En el reverso de esta moneda, dos venatores, uno con lanza, en la parte inferior, otro con espada y escudo, en la parte superior, enfrentan cada uno a un felino que se les abalanza; un jabalí descansa herido junto al venator superior.

\footnotetext{
${ }^{12}$ Por ejemplo, el que Jenofonte describe sobre Ciro (Xen., An., 1, 2, 7): “un gran paradeisos lleno de animales salvajes, que aquel [sc. Ciro] cazaba a caballo cuando quería ejercitarse a sí

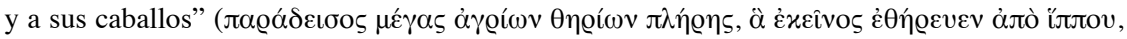

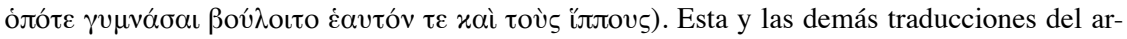
tículo son propias.

${ }^{13}$ Isocr., Antid., 15, 213.

${ }^{14}$ Epplett 2014, p. 506.

${ }^{15}$ Plaut., Poen., 1011-1012.

${ }^{16}$ Liv., 39, 22.

${ }^{17}$ Epplett 2014, p. 508.

${ }^{18}$ Interesante aquí el malogrado efecto de la carnicería de elefantes en la venatio de Pompeyo, que César usó para su ventaja en sus juegos (cf. Cic., Fam., 7, 1, 3; Plin., HN, 8, 20-21).

${ }^{19}$ Andreae 1990, p. 106. L. Livineyo Régulo fue praetor bajo Julio César (43/42 a. C.: la moneda sería conmemorativa para la ocasión). Durante la guerra en África (46 a. C.), Livineyo había tenido al mando Hadrumetum (cf. Bell. Afr., 89): quizás había podido obtener de ahí fácilmente los felinos para sus venationes.
} 
Se suele ver en este boom venatorio, por así decir, de la época cesariana el patrón que posteriormente sirvió de modelo a los emperadores en la siguiente fase de la historia de Roma: ${ }^{20}$ Augusto se jacta en sus Res gestae (22) de haber organizado para el pueblo 26 venationes bestiarum Africanarum. En ellas perecieron cerca de 3,500 animales. ${ }^{21}$ Según Dion Casio, en una sola venatio organizada por Nerón en el 55/56 d. C. murieron 300 leones y 400 osos a manos de guardias imperiales, ${ }^{22}$ mientras que para la inauguración del enorme Anfiteatro Flavio, bajo Tito y Domiciano ${ }^{23}$ (80 d. C.), murieron en 100 días 9,000 animales. A partir de entonces este sería el principal escenario en Roma para tales espectáculos; Dion Casio incluso

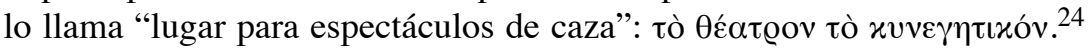

Sería muy largo referir los juegos que organizó cada emperador en Roma, incluso destacando solo los más importantes, como los de Trajano ${ }^{25}$ o Adriano, ${ }^{26}$ Cómodo o Caracalla, hasta bien entrada la época tardoantigua con Constantino, Honorio o incluso Odoacro y Teodorico el Grande..$^{27} \mathrm{Me}$ limito a subrayar, una vez más, retomando el análisis de Epplett, ${ }^{28}$ el valor político que nace de la popularidad de que gozaron las venationes en la Roma imperial.

A continuación, expongo cómo tal valor se observa de manera particular en la poesía, como un discurso de panegírico imperial y de crítica. Para ello me concentraré en la literatura que floreció entre el reinado de Nerón y el

${ }^{20}$ Epplett 2014,pp. 508-509.

${ }^{21}$ Res. gest. div. Aug., 22: venationes bestiarum Africanarum meo nomine aut filiorum meorum et nepotum in circo aut in foro aut in amphitheatris populo dedi sexiens et viciens, quibus confecta sunt bestiarum circiter tria millia et quingentae. Como apunta Epplett 2014, p. 510 , esto da un promedio de 135 bestias por espectáculo. Hay que notar también las diferentes locaciones de los espectáculos que menciona el texto: el Circo (Máximo) o construcciones provisionales a manera de anfiteatro en el foro o en otros lugares.

22 Dio Cass., 61, 9 (espectáculo neroniano); 66, 25 (inauguración del Anfiteatro Flavio).

${ }^{23}$ Con Domiciano, la organización de las venationes se convirtió en una prerrogativa imperial, es decir que los magistrados y ciudadanos que deseasen (y pudiesen) organizarlas debían pedir una autorización explícita del emperador (Wiedemann 1992, p. 8).

${ }^{24}$ Dio Cass., 66, 25, aunque actividades como luchas de gladiadores y naumaquias eran parte, naturalmente, de los espectáculos.

${ }^{25}$ Dio Cass., 68, 15.

${ }^{26}$ Hist. Aug., Hadr., 3, 8; cf. CIL XIV 4546.

${ }^{27}$ Para un panorama histórico de las venationes hasta finales de la época imperial remito a Epplett 2014, pp. 509-511. Coleman 2006, pp. lxxii-lxxv llega hasta la época flavia. Sobre la supervivencia de los espectáculos circenses en la época tardoantigua, remito a Puk 2014, en particular cap. IV, pp. 229-288 (sobre las venationes: pp. 264-288). Puk proporciona también las siguientes fechas como límites temporales de los juegos circenses, sobre todo referidos a las venationes (pp. 381-383): s. vi para Hispania, Galia e Italia, y ss. vI-VII para el norte de África y el oriente romano (única excepción, la ciudad de Constantinopla, donde exhibiciones y peleas de animales en el Hipódromo están documentadas al menos hasta el s. XII).

${ }^{28}$ Epplett 2014, p. 509. 
de Domiciano, incluso Trajano (ss. I-II). Dejo para una futura publicación el llamado revival ${ }^{29}$ de la literatura flavia bajo Teodosio y Honorio en los años de transición entre los ss. IV y v, en especial bajo la regencia de Estilicón.

\section{LITERATURA CINEGÉTICA Y VENATIO}

Habría que hacer una pequeña aclaración respecto a la poesía cinegética en general, y al tema de la venatio en concreto. La cinegética, es decir la exposición de los métodos de caza, particularmente a través de perros azuzados (de ahí el nombre), es un tema popular en la poesía hexamétrica (didáctica). Sus representantes más destacados son Gratio en época augústea, Pseudo Opiano (u Opiano de Apamea) en el s. II y Nemesiano en el s. III, estos últimos con una poesía griega y otra latina respectivamente. ${ }^{30}$

Ahora bien, materialmente, la cacería y la recolección de animales es el primer paso que antecede a la organización de un espectáculo venatorio en la arena, le seguiría el transporte de las bestias a Roma, o a la ciudad donde los ludi se llevarían a cabo. Temáticamente, una obra poética de cinegética se presta bien para fines panegíricos. ${ }^{31}$ No obstante, el tema del espectáculo de caza en la arena, la venatio, no es exactamente igual. En el periodo tardoantiguo la representación de la cacería, recolección y transporte de animales para el específico uso de las venationes en la arena son elementos importantes para el discurso panegírico oficial y privado, ante todo en las representaciones musivas, como el célebre mosaico de la "Gran Caza" de Piazza Armerina y otros mosaicos coetáneos del norte de África, pero también en la literatura, como las poesías políticas de Claudiano. Sin embargo, es exactamente la especificidad de la venatio como objetivo último, el elemento distintivo para su interpretación. Este elemento falta casi por completo en los tres poetas didácticos mencionados arriba, motivo por el cual este tipo de literatura en general, y estas obras en particular, no van a ser consideradas en el presente artículo. ${ }^{32}$ De manera contraria, en los ejem-

\footnotetext{
${ }^{29}$ Sobre esto, cf. Cameron 2000.

${ }^{30}$ Acerca del Cynegeticon de Gratio, cf. Verdière 1964; Formicola 1988; Green 2018. Sobre los Cynegetica de Pseudo Opiano (u Opiano de Apamea), cf. Garzya 1957; Silva Sánchez 2002; Papathomopoulos 2003; Renker 2020. Para los de Nemesiano, cf. Jakobi 2014.

${ }^{31}$ Considérese el proemio de las Cynegetica de Nemesiano, con la recusatio tópica en el exordio del poema (vv. 1-14), celebrando a los emperadores Numeriano y Carino (años 283285) y posponiendo un poema épico-panegírico en su honor: cf. Jakobi 2014, pp. 3 s.; 84-92; acerca del particular del exordio épico panegírico, Schindler 2009, pp. 26-30.

32 Por supuesto juegan un papel importante para el análisis de la obra claudianea: para los Cynegetica de Pseudo Opiano en Claud., 24 (Stil. 3), 339-341, cf. Ryser 2015.
} 
plos literarios que se muestran a continuación, el papel de la caza en sí juega un papel secundario, pues es el desarrollo de la acción en la arena lo que se encuentra en el centro del discurso.

\section{VENATIO EN LA POESía IMPERIAL: LITERATURA Y VENATIONES bajo Nerón y Domiciano}

En el periodo imperial, es interesante notar que sobre todo bajo dos emperadores, tradicionalmente connotados de manera negativa pero íntimamente ligados al fomento de la producción literaria (y también conocidos por su afición a los espectáculos), la venatio se volvió un tema importante en la poesía y en particular con función panegírica: Nerón y Domiciano. ${ }^{33}$

\section{a) Función panegírica}

El primer autor en tematizar la puesta en escena de una venatio imperial en la literatura latina es Calpurnio Sículo en la séptima égloga. Se refiere, casi con certeza, al espectáculo que Nerón dio en un anfiteatro de madera que había mandado construir ex profeso cerca del Campo Marte en el año 57.34

El peso panegírico resulta evidente. De hecho, después de las Églogas, 1 y 4 , la séptima cierra, por así decir, el ciclo de índole política/panegírica dedicado al gran nuevo saeculum neroniano, ${ }^{35}$ y lo hace precisamente con la descripción de la venatio.

En esta égloga, el rústico Coridón había ido a la Urbe. Puesto que se ha tardado en volver al campo más de lo debido, su compañero Licotas lo apostrofa y pregunta la causa de su demora (lentus ab urbe venis..., 1). Mediante una alternancia de respuestas (1-22), a la manera típica del carmen amoebeum bucólico, Coridón describe con asombro lo que lo entretuvo en la ciudad: "los espectáculos que el joven dios [i. e. Nerón] había ofrecido en la amplia arena" (spectacula.../, quae patula iuvenis deus edit harena, 5

\footnotetext{
${ }^{33}$ Sobre los cambios en la codificación literaria de estos dos emperadores, famosos por oscilar entre divinización in vita y 'satanización' post mortem, así como por su inclinación a las artes y al espectáculo, cf. Charles 2002 y Cordes 2017. Para un estudio acerca de la poesía como medio de representación de Domiciano, cf. Leberl 2004.

${ }^{34}$ Cf. Tac., Ann., 13, 31; Suet., Ner., 12; Dio Cass., 61, 9, 5, resalta más el espectáculo acuático. Sobre la égloga en particular, cf. Gnilka 1974; Korzeniewski 1976; Vinchesi 20177, pp. 148-158; Cordes 2017, pp. 63-66. Convincente para la cronología de Calpurnio en época neroniana (donde la Égloga, 7, juega un papel central), cf. Townend 1980, en concreto pp. 169174. A partir de aquí, los años indicados son todos d. C.

${ }^{35}$ Cf. Karakasis 2016, sobre todo pp. 15-119; para la Égloga, 7, véanse pp. 87-119; en cuanto a la relación entre la Ecl., 1 y la 7, cf. Korzeniewski 1976.
} 
s.), y lo contrapone a la monótona vida rústica que su compañero tuvo que soportar en su ausencia. ${ }^{36}$ A continuación sigue la detallada descripción de los spectacula (23-72), el pasaje central de la égloga. Concluido esto, Licotas expresa su maravilla y júbilo por poder vivir los saecula de Nerón, y pregunta si acaso Coridón tuvo la oportunidad de ver de cerca al emperador (73-78). Este responde finalmente que no fue posible más que verlo solo de lejos, pero aun así había reconocido en él la belleza conjunta de Marte y Apolo (79-84).

Antes de iniciar a un análisis más detallado de la égloga, quisiera detenerme en el pasaje central, la descripción de la venatio neroniana. Podría estructurarse de la siguiente manera: descripción del anfiteatro (spectacula) de madera (in caelum trabibus spectacula textis, 23), donde estaban sentados los diferentes rangos sociales (23-26). El escenario elíptico puesto como si fuera un bosque (cf. vallis, 30 silvae, 31 montes, 32) (30-34). La estupefacción de Coridón y la charla con un vecino de asiento, más anciano (senior, 39), quien le segura que todos los espectáculos vistos hasta entonces no tienen valor en comparación con el presente (35-46). Descripción de las partes estructurales, ricamente adornadas, y los complejos mecanismos del anfiteatro (47-56). Descripción de las fieras (57-68). Sorpresa ante el cambio repentino de escenarios en la arena (69-72).

La descripción de las fieras (genus omne ferarum, 57) podría subdividirse a su vez en dos fases: los animales terrestres (58-63) y los acuáticos (64-68). Si bien un problema textual quizás excluye el v. 59 y las perífrasis descriptivas que Calpurnio pone en boca de Coridón hacen difícil una identificación segura de las especies descritas, ${ }^{37}$ los animales terrestres que encontramos son mayoritariamente bovinos, liebres, "jabalíes" y osos; los acuáticos se reducen a las focas y los hipopótamos del Nilo:

ordine quid referam? uidi genus omne ferarum, hic niueos lepores et non sine cornibus apros, [hic raram siluis etiam, quibus editur, alcen]. ${ }^{38}$ uidimus et tauros, quibus aut ceruice leuata deformis scapulis torus eminet aut quibus hirtae

\footnotetext{
${ }^{36}$ Esta inesperada inversión es el núcleo del fondo panegírico de la égloga, como anota Gnilka 1974,pp. 129 s. Cf. infra.

${ }^{37}$ Gnilka 1974 argumenta, a mi parecer, convincentemente por la poca idoneidad del v. 59 (pace Korzeniewski 1976, pp. 252-253): este es un verso que presenta, en la tradición manuscrita, lecturas diferentes e insatisfactorias. Debe ser resultado de una glosa interpolada en un estadio primigenio de la transmisión. Además, Coridón describe animales, como se verá, con naive Anschaulichkeit (Gnilka 1974, p. 135), es decir, con la visión ingenua de un campesino que usa perífrasis para describir animales exóticos que no conoce, comparándolos con los animales rústicos que le son familiares. En este contexto, la mención directa de un alce es poco conveniente.

${ }^{38}$ Sigo a Gnilka al poner entre corchetes este verso (v. n. supra).
} 
iactantur per colla iubae, quibus aspera mento

barba iacet tremulisque rigent palearia setis. nec solum nobis siluestria cernere monstra contigit: aequoreos ego cum certantibus ursis spectaui uitulos et equorum nomine dictum, sed deforme pecus, quod in illo nascitur amne qui sata riparum uernantibus irrigat undis.

¿Qué te puedo referir en orden? Vi toda clase de fieras:

Aquí liebres blancas como la nieve y unos jabalíes con cuernos, [aquí un animal que incluso en los bosques, donde nace, es difícil de ver, el alce]. Vimos también toros a los que, al levantar el cuello, les sale una protuberancia deforme de la espalda, u otros que sacuden de la nuca una melena hirsuta, les cuelga del mentón una barba áspera y donde llevarían el yugo tienen rígidos pelos que se agitan.

Y no solo nos tocó ver monstruos del bosque:

También vi unos becerros marinos con unos osos que peleaban, y el ganado llamado con el nombre de caballo pero es deforme, que nace en aquel río que irriga los campos de sus orillas cuando se inunda en primavera. ${ }^{39}$

Coridón parece no describir una venatio cruenta, sino más bien un espectáculo pacífico; ${ }^{40}$ no obstante, la señal que indica una lucha de animales la encontramos en el v. 65, donde se especifica que las focas, o "becerros" marinos, acompañaban a unos osos con los que luchaban (véase $\mathrm{cum}^{41} \mathrm{cer}$ tantibus ursis, 65); y también la presencia de grandes "toros" y "jabalíes" cornudos permite imaginar momentos de azuzamiento. Es notable cómo Coridón describe animales que él, como rusticus, desconoce. Esto se distingue al hacer él analogías con animales del campo, como anota Gnilka. ${ }^{42}$ De qué animales se trata específicamente no es del todo claro: con seguridad los "jabalíes" con cuernos y los dos tipos de "toros", uno con joroba y otro hirsuto, se refieren a especies exóticas de la India y/o de África. ${ }^{43}$ De ahí

\footnotetext{
${ }^{39} \mathrm{He}$ hecho cortes adecuados a los versos latinos en el texto traducido semánticamente para facilitar la ubicación de los equivalentes versos latinos.

${ }^{40}$ También la descripción de Suetonio subraya el carácter pacífico de esas venationes (Suet., Ner., 12), donde no hubo condenados a muerte. Una representación iconográfica que, a mi parecer, muestra un carácter similar, a pesar de ser del s. III, es el panel central del mosaico de Lod, cf. Ovadiah-Mucznik 1998, pp. 3-6.

${ }^{41}$ Para el uso del cum aquí enumerativo, cf. Vinchesi 2014, pp. 504 s., quien remite a TLL IV $1377,42$.

${ }^{42}$ Gnilka 1974, pp. 135 s.

43 Para el "jabalî" con cuernos se han propuesto identificaciones con el babirusa (identificable con la descripción de Plin., $H N, 8,212$ ) o, más probablemente, con el facóquero común (identificable con la descripción de Ael., $H A, 7,27)$. Para los "toros", se piensa en general en el
} 
en fuera son fácilmente identificables las liebres blancas, ${ }^{44}$ las focas, ${ }^{45}$ los ${ }^{0 s o s}{ }^{46}$ y los hipopótamos ${ }^{47}$ Esto tampoco es crucial para el presente artículo. ${ }^{48}$ Lo importante es notar que se trata de especies exóticas que subrayan el poder del emperador y, sobre todo, recalcan el carácter panegírico de la égloga: el anciano que interpela a Coridón le asegura nunca haber visto nada similar en cuanto a lujo y magnificencia:

"en ego iam tremulus iam uertice canus et ista factus in urbe senex stupeo tamen omnia: certe uilia sunt nobis, quaecumque prioribus annis uidimus, et sordet quicquid spectauimus olim”.

\begin{abstract}
"Incluso yo, ya tembloroso, ya con la cabeza cana y vuéltome anciano en esta ciudad, admiro con estupor todo. Claro que me parece sin valor todo lo que he visto los años pasados, y resultan miserables los espectáculos de antes".
\end{abstract}

Las palabras del senior son pesadas: los espectáculos anteriores a este son calificados como vilia y el verbo que los caracteriza subraya la suciedad con las que se les compara (sordere). Coridón está ahora convencido de la penuria del campo, por eso desde su primera intervención en la égloga

cebú, por su característica joroba, y en el bisonte europeo por su pelaje (además de ser un animal bastante popular para grandes venationes). Cf. Vinchesi $2017^{7}$, ad loc.

${ }^{44}$ Probablemente las liebres alpinas, de las que habla Plin., $H N, 8,217$.

${ }^{45}$ Sin duda se habrá tratado de un ejemplar de foca monje del Mediterráneo. La participación de focas en las venationes no está testimoniada en otras fuentes clásicas: Vinchesi $2017^{7}$, ad loc. No obstante, en el texto griego apócrifo del Acta Pauli et Theclae aparecen de nuevo, esta vez como peligrosos monstruos marinos (34 L.): esto es en parte resultado de la (mala) recepción del presente pasaje en el autor del texto apócrifo: Schneider 2001. Un monstruo marino (¿una foca?) se encuentra en el medallón del Mosaico de Lod. La designación habitual para estos animales en latín es el griego phoca (típico en poesía: Verg., Georg., 4, 432; Ov., Met., 1, 300) o vitulus marinus (cf. L\&S, s. v. vitulus II B, con fuentes, más común en prosa). Coridón, como rusticus, usa una locución descriptiva que da al pasaje un carácter peculiar (cf. n. infra).

${ }^{46}$ Quizás los temibles osos africanos (v. infra) u osos europeos. La identificación con osos polares no es convincente (pace Toynbee 1973, pp. 93 s.; cf. también Karakasis 2016, p. 100, n. 54 con más bibliografía): eran desconocidos en la Antigüedad (cf. Keller 1909, p. 180). Más convincentes son Gnilka 1974, p. 134, o Townend 1980, p. 171. Para un tratamiento de la cuestión, Di Salvo 1990, pp. 30 s. y 120 s.

${ }^{47}$ Coridón describe al hipopótamo como un "caballo" deforme proveniente del río Nilo, una alusión etimológica y descriptiva un tanto intricada, pero voluntaria para dejar ver la ingenuidad y la sorpresa del rusticus. Sobre el lenguaje que emplea Coridón, cargado de "coloquial idiom", cf. Karakasis 2016, pp. 88-89.

48 Karakasis 2016, p. 99, ve en la presentación de estos animales la expresión del locus horridus, característica del gusto neroniano (hace una comparación con Lucan., 6, 507 ss.), en contraposición con el locus amoenus del gusto de época augústea. 
compara despectivamente las "viejas hayas" del campo, símbolo por antonomasia de la paz bucólica en Verg., ecl., 1, 1, ${ }^{49}$ con los sofisticados espectáculos que ofrece el emperador: 5-6. ${ }^{50}$ Después de la descripción de la venatio en Roma, incluso Licotas está de acuerdo: tener la fortuna de vivir los años de juventud bajo un emperador tan divinamente dadivoso ${ }^{51}$ (indulgente deo, 75) es un verdadero motivo de bienaventuranza, por eso apostrofa dos veces a Coridón como felix $(73,74)$.

La égloga finaliza con Coridón que describe el instante donde de lejos vislumbró al emperador (un venerandum numen, en palabras de Licotas: 76, y mea numina, en palabras de Coridón: 80): en su rostro se confunde la fuerza y la belleza de Marte y Apolo (in uno / et Martis vultus et Apollinis esse putavi, 83-84), un evidente discurso panegírico, donde el poeta presenta al emperador con rasgos divinos. ${ }^{52}$ Nerón ha doblegado la naturaleza al crear un enorme anfiteatro de madera (cf. la descripción en los vv. 23-24, donde la construcción parece un bosque artificial que se eleva hacia el cielo), con escenarios que recrean distintos paisajes y animales exóticos que interactúan entre sí de modo supranatural. El espectáculo de Nerón, según las palabras del senior en vv. 43-46, supera y rebasa todos los espectáculos que se habían dado hasta ese momento, así como Nerón mismo rebasa y supera a todos los emperadores anteriores. Un nuevo saeculum de oro ha llegado.

La tópica superioridad del campo sobre la ciudad ha sido completamente invertida gracias a la indulgentia del emperador, aquí radica la clave del discurso panegírico de Calpurnio en esta égloga.${ }^{53}$ Esta indulgentia toma forma

${ }^{49}$ Sobre la relación entre Verg., Ecl., 1, 1, y Calp., Ecl., 7, cf. Karakasis 2016, pp. 90-92, y para la relación metapoética del fagus como la poesía pastoral virgiliana, p. 91.

${ }^{50}$ Apóstrofe de Coridón a Licotas, pues este prefiere los veteres fagi a los nova spectacula en Roma (Calp., Ecl., 7, 5 s.). La inversión es aún más evidente si se considera que el adjetivo patulus en Virgilio se refería al fagus bajo el cual descansa Títiro (Verg., Ecl., 1, 1), mientras en Calpurnio se refiere a la arena del anfiteatro (v. 6).

${ }^{51}$ Como se verá, estos son conceptos que refieren a la "generosidad" del emperador al organizar los juegos. Conceptos como indulgentia o magnanimitas (incluso el "equivalente" griego $\mu \varepsilon \gamma \alpha \lambda o \psi v \chi_{i ́ \alpha} \alpha$, presente en el mosaico tardoantiguo de Yakto, Siria) indican el nivel material económico de la "generosidad" y la superioridad espiritual del emperador. Sobre la magnitudo animi romana, en un sentido filosófico, pero más bien político, y la $\mu \varepsilon \gamma \alpha \lambda \mathrm{o} \psi v \chi i ́ \alpha$ aristotélica, cf. Knoche 1935, sobre todo pp. 74-88; cf. también Aymard 1951, pp. 555 s. (enfocado al periodo bajo Cómodo). Para el mosaico de Yakto y su contexto evergético típicamente romano (oriental) tardoantiguo, cf. Dunbabin 2016, pp. 237-239. Resulta evidente la continuidad de este fenómeno.

${ }^{52}$ Lecturas e negativo de la égloga (como críticas a Nerón por asociar a Marte negativamente), por ejemplo, Leach 1973, pp. 77-89, no son convincentes: cf. Karakasis 2016, pp. 110-113.

${ }^{53}$ Gnilka 1974,pp. 129 s. Karakasis 2016, p. 119, considera, por este motivo, la descripción de la venatio de Calpurnio como base de la poesía panegírica al emperador (laudes principis) con temática venatoria; sin poder definir más este género a falta de otros textos o testimonios fuera del presente, así como de las conocidas composiciones de Marcial (Spect.) y Estacio 
en la construcción del elegantísimo anfiteatro de madera y de la venatio con animales exóticos que el emperador ofrece al pueblo.

Marcial, veintitrés años después del espectáculo neroniano (es decir, en el año 80), fue comisionado por los nuevos emperadores flavios para celebrar con una serie de epigramas la inauguración del colosal anfiteatro que conocemos hoy con el nombre de Coliseo, el Amphitheatrum Flavium, ubicado exactamente en los terrenos que había ocupado un lago artificial de Nerón. ${ }^{54}$ Para esto, ideará un interesante discurso panegírico a través de breves composiciones con tema circense.

Tito y Domiciano son los emperadores a cargo luego de la muerte del padre Vespasiano en 79. Tras la muerte de Tito en 81, Domiciano reinó hasta su asesinato en 96. Poetas como Estacio y Marcial jugaron, hasta ese año, un papel importante en el discurso panegírico imperial. Después de esa fecha, Marcial intentó justificar su posición ante el nuevo emperador, Nerva y luego Trajano ${ }^{55}$ (Estacio ya había muerto). Con esta justificación nacerán nuevas voces que condenarán ahora abiertamente el régimen de Domiciano, como el mismo Marcial en sus últimos libros y sobre todo Juvenal en la Sátira, $4{ }^{56}$ Como quiero mostrar, la tematización de la venatio desempeña también aquí un papel importante tanto en la poesía a favor, como en aquella en contra del emperador.

El spectaculorum Liber ${ }^{57}$ consta de una serie de poco más de 30 epigramas ${ }^{58}$ En ellos, Marcial tematiza distintos aspectos del anfiteatro, la política imperial y describe vívidamente escenas de condenas ad bestias, venationes, combates, etc. El primer epigrama presenta el Caesareum Amphitheatrum (Mart., Spect., 1, 6) como la nueva maravilla arquitectónica de la ecúmene. El segundo aclara que su inauguración simboliza la restitución del bien

(Silv.). Juzgo pertinente notar cómo un tema, como el venatorio, contribuye dentro de un marco literario más amplio, a un discurso panegírico que irá más allá de la época imperial.

${ }^{54}$ Mart., Spect., 2, 4-5. Cf. Suet., Vesp., 9, 1; también Dio Cass., 66, 25. Para un estudio general, véase Coleman 2006, pp. 1xv-lxxii.

${ }^{55}$ Cf. por ejemplo Mart., 10,72, y Cordes 2017, pp. 166-171. Para el fenómeno del cambio (aunque al mismo tiempo, también de continuidad) en la literatura tras el asesinato de Domiciano con Nerva y Trajano, cf. Coleman 2000, sobre Marcial pp. 33-39.

${ }^{56}$ Dos monografías útiles para el análisis del discurso en torno al cambio de código -o decostrucción- en la alabanza y condena de Nerón y Domiciano en poesía y prosa son Cordes 2017 y Schulz 2019.

57 Acerca de la cuestión abierta sobre el título, cf. Coleman 2006, pp. xxv-xxix. El más verosímil es Liber spectaculorum.

${ }^{58}$ Son 33 epigramas siguiendo la numeración de Lindsay 1929². Shackleton Bailey (SB) 1990 sigue a Carratello 1981 y divide algunos epigramas de manera distinta, por lo que llega a un total de 37 epigramas (Carratello omite el último epigrama y numera 36, cf. infra). Coleman 2006 adopta esta última numeración y omite igualmente el Epigrama, 37. En el presente artículo sigo el texto y la numeración de Lindsay e indico entre paréntesis la de Shackleton Bailey (SB). 
público a los ciudadanos, en oposición al acaparamiento sufrido antes a manos de Nerón, quien tenía para sí aquel terreno (Spect., 2, 11-12). El tercero subraya la gran afluencia de público de todos los rincones el imperio, y el cuarto deja en claro que el régimen de terror neroniano ha terminado (Spect., 4). Del 5 al 30 (= 33 SB) Marcial describe diversos momentos de los ludi (condenas a muerte, gladiadores y gladiadoras, venationes, naumaquias), a veces con un particular gusto por lo macabro, sobre todo en los epigramas relativos a condenados ad bestias. ${ }^{59}$

Para este artículo, limitado a las representaciones de venationes con fines panegíricos, resalta a mi parecer como primer caso el Epigrama, 10 (= 12 SB). Como señala Kathleen Coleman, no se trata de una venatio propiamente dicha, sino de un espectáculo con un animal amaestrado. Sin embargo, la interacción hombre-animal se lleva a cabo en un contexto amplio de espectáculos venatorios. El núcleo panegírico radica en la idea de la autoridad que el emperador tiene incluso sobre los animales salvajes (principalmente leones), ${ }^{60}$ símbolo de la fuerza de la naturaleza. Esto será un continuum tanto en Marcial como en Estacio, pero es también el núcleo del discurso panegírico imperial a través de la venatio.

En este epigrama Marcial describe un acto en que un domador de leones (magister, 1) ${ }^{61}$ es agredido de manera inesperada por su ingratus leo (1). Ante tal 'atrevimiento' (tanto... crimine, 3) por parte del león, se ordenó su muerte por golpes de lanza (et qui non tulerat verbera, tela tulit, 4). El dístico final recalca el motivo panegírico y lo explicita:

quos decet esse hominum tali sub principe mores, qui iubet ingenium mitius esse feris!

$$
\text { (Mart., Spect., } 10 \text { [= } 12 \text { SB], 5-6) }
$$

¡Qué costumbres de la sociedad tiene que haber bajo tal emperador que ordena que el ánimo de las fieras sea suave!

El epigrama juega con la idea de que incluso la fiereza de las bestias cede ante la razón que representa el emperador. No solo los mores hominum están supeditados a la superioridad moral del emperador, sino incluso la naturale-

\footnotetext{
${ }^{59}$ Destaco Mart., Spect., 5; 7 (= 9 SB); 8 (= 10 SB). Por crueldad animal sobresalen Mart., Spect., $12-14$ (= 14-16 SB).

${ }^{60}$ Coleman 2006, ad loc. El león y el elefante son los animales regios por excelencia (cf. Sen., Clem., 1, 5, 5), cf. también infra.

${ }^{61}$ Para la consideración antigua de la gran habilidad de los entrenadores de animales (magistri), cf. Newlands 2011, p. 192: "animal trainers at Rome were highly skilled (Sen. Ep. 85.41; Plut. Mor. 968b-e; Plin. NH. 8.2-3; Beagon 1992, 128-129)”. Según Plinio, Marco Antonio fue el primero en Roma en presentar leones domados mientras arrastraban un carro (cf. Plin., $H N$, 8, 55, y Van Dam 1984, p. 371).
} 
za o ánimo (ingenium, 6) de las bestias más salvajes y peligrosas - aunque sea de manera coercitiva - ${ }^{62}$ Como se verá, este concepto, a nuestros ojos seguramente poco convincente, es la base del discurso panegírico imperial, referido a (y ejemplificado con) los espectáculos con animales ${ }^{63}$ Esto aplica tanto para el caso en que el espectáculo salga según lo planeado, y la fiera (y con ella el público lector) reconozca (y por ende sea reflejo) la superioridad casi divina del emperador; como para el caso en que el animal se rebele y sea abatido por la voluntad imperial, volviéndose igualmente símbolo de la superioridad del soberano. Veremos ejemplos para ambos casos.

El Epigrama, 17 (=20 SB), menciona la sumisión de una fiera ante la grandeza del emperador: un elefante se arrodilla ante el emperador; Marcial lo presenta como signo de sumisión y adoración (1). La índole de fiera, es decir que infunde miedo, es subrayada en el segundo verso. El dístico final explicita, como en el caso del epigrama anterior, la intención panegírica (34). A continuación cito el epigrama entero:

Quod pius et supplex elephas te, Caesar, adorat, hic modo qui tauro tam metuendus erat, non facit hoc iussus nulloque docente magistro: crede mihi, nostrum sentit et ille deum.

(Mart., Spect., 17 [= 20 SB])

Que un elefante respetuoso y suplicante, César, te muestra adoración, él, que hace poco infundía tanto miedo a un toro.

No hace esto obligado o enseñado por ningún domador; créeme, él también percibe [la presencia de] nuestro dios.

La caracterización del elefante recalca, evidentemente, su naturaleza casi humana ${ }^{64}$ es pius et supplex además de que adorat al emperador, es decir, tiene un sentido de responsabilidad moral y sagrada que lo lleva a reconocer la grandeza o divinidad del emperador y mostrarse indefenso y suplicante ante ella. De hecho, el elefante y el león, animales regios por antonomasia, ejemplifican ya en Séneca la actitud magnánima y clemente. ${ }^{65} \mathrm{Al}$ mismo tiempo, su estado de fiereza aquí es recalcado por el metuus que había in-

\footnotetext{
${ }^{62}$ Sobre ingenium para referirse a la naturaleza de un animal, cf. en poesía: Ov., Am., 1, 10; Met., 15, 85-87; Verg., Georg., 1, 415 s.

${ }^{63}$ Coleman 2006, ad loc.: "The absurdity of attributing moral responsibility to animals is subordinate to the requirements of panegyric".

${ }^{64}$ El elefante suele asociarse al espíritu humano (cf. Cic., Nat.D., 1, 97; Fam., 7, 1, 3; Plin., $N H, 8,1$ ss.), aquí aparece particularmente humanizado con los adjetivos pius y supplex, característicos de quien sigue los preceptos y las responsabilidades morales hacia los dioses, la patria y la familia (como Eneas) y de quien es indefenso y acepta voluntariamente someterse. Sobre la adoratio que hacen los elefantes, cf. Plin., $H N, 8,3$, y Coleman 2006, ad loc.

${ }^{65}$ Cf. Sen., Clem., 1, 5, 5 .
} 
fundido poco antes en la arena al toro (hic modo qui [sc. elephas] tauro tam metuendus, 2), un animal que representa la fuerza bruta de la naturaleza por su índole aguerrida y peligrosa: véase p. e. el Epigrama, 16b (= $19 \mathrm{SB})$. La espontaneidad con que el elefante actúa es, finalmente, la prueba irrefutable, argumenta Marcial, de que el elefante reconoce la magnanimidad del emperador (y divinidad, pues el poeta habla de él como noster deus: v. 4). La conclusión es que el emperador recibe, a través de este epigrama, la alabanza y el reconocimiento con lo divino, no solo por parte del elefante, sino del poeta y del público.

Una estrategia similar la encontramos en el Epigrama, 30 (= $33 \mathrm{SB})$ : un cérvido, quizás un gamo común (dama dama), huye de una jauría de veloces molosos (1). Haciendo tiempo, esquivando, corriendo y saltando (2), termina finalmente por detenerse suplicante (supplex, 2) ante los pies del emperador, como si estuviera rogando por su vida (similisque roganti constitit, 3). Los canes se detienen también y no atacan al cérvido (4), como mostrando su respeto lleno de temor hacia el emperador. Al parecer hay a continuación una laguna en el texto, ${ }^{66}$ pero el sentido general es claro: el emperador entiende lo sucedido como un donum que se le ha hecho (5), un signo de sumisión de los animales que reconocen su divinidad (esta es especificada en el v. 6: cf. numen, sacra potestas). El poeta finaliza el epigrama con una sentencia, en la que da (como en el epigrama anterior) la prueba irrefutable de que los animales reconocen y perciben la presencia del divino emperador, algo semejante no puede ser resultado del amaestramiento: "creed: las fieras no han aprendido a mentir" (credite: mentiri non didicere ferae, 7 ) ${ }^{67}$

En el primer libro de los Epigramas se encuentra una serie de composiciones con un tema complejo, que oscila entre el panegírico y, como notó Niklas Holzberg 1988, la figura del poeta en busca de defensa y patrocinio (imperial), el llamado ciclo del león y la liebre. ${ }^{68}$ Refieren con probabilidad a un espectáculo en el Anfiteatro Flavio, organizado por Domiciano en el año $83 .{ }^{69} \mathrm{El}$ núcleo narrativo es un león en la arena que, a pesar de su

\footnotetext{
${ }^{66} \mathrm{Al}$ menos en parte de la tradición manuscrita. Quizás aquí se especificaba algún detalle del "milagro" que presencia el emperador. Cf. Coleman 2006, ad loc.

${ }^{67}$ Para un juego con el Epigrama, 4, 74, cuya conclusión panegírica sería que "the emperor is capable of turning saeuitia into clementia", cf. Coleman 2006, p. 1xxx, n. 175.

68 Mart., 1, 6; 14; 22; 44; 48; 51; 60; 104. Sobre este tema, destacan Weinreich 1928, pp. 90-109; Howell 1980, pp. 118 ss.; Holzberg 1988, pp. 74-85 (en torno a la relación del poeta indefenso/liebre y el emperador poderoso/león, cf. 1, 60, 5, donde el león es llamado dominus y rex, fórmula del patronus por antonomasia, el emperador); Walter 1996, pp. 63-65; Nauta 2002, pp. 408-412; Leberl 2004, pp. 272-276; Coleman 2006, p. xx; Cordes 2017, pp. 187 s. Véase también Flores Militello 2019, pp. 148 s.

${ }^{69}$ Probablemente para celebrar su triunfo sobre los catos en Germania (cf. Suet., Dom., 6, 1). Para Tácito (Agr., 39; Germ., 37, 5) y Dion Casio $(67,5)$ era claro que se trataba de un falso triunfo (cf. Jones 2002, pp. 128-129). Domiciano tenía, como se sabe, una fuerte pasión por los
} 
ferocidad, juega dócilmente con su víctima, una liebre. Marcial pone abiertamente la actitud del león en relación con el hecho de que este reconoce y es 'contagiado' por la divinidad de Domiciano, por lo tanto se muestra dócil y clemente. Por ejemplo, en el Epigrama, 1, 6, la voz del poeta compara el rapto de Ganímedes con el espectáculo del león en la arena: así como el águila de Júpiter no lastimó al suave puer con sus garras al raptarlo (1-2), así los Caesarei leones cedieron a las súplicas de la liebre que juega ya despreocupada en sus fauces (3-4) ${ }^{70}$ Ambos acontecimientos son calificados como miracula (5) en el dístico final, mientras se pregunta por el más importante de ambos:

Quae maiora putas miracula? summus utrisque auctor adest: haec sunt Caesaris, illa Iovis.

(Mart., 1, 6, 5-6)

¿Cuál crees que sea el milagro más grande? El autor de ambos es alguien excelso: de este es el César; de aquel, Júpiter.

Aquí Marcial no solo afirma que el león reconoce la majestad del emperador, sino que compara a este último con Júpiter mismo. ${ }^{71}$ Con esto el poeta subraya el carácter divino de Domiciano. ${ }^{72}$

En el Epigrama, 14, Marcial retoma el asunto: explícitamente aclara que, entre los spectacula de la arena, el 'show' de los leones y la liebre, es una especie de 'intermezzo lúdico', los términos que usa son claros: deliciae, lusus iocusque, vv. 1-2. Vuelve a describir lo sucedido (3-4). En el dístico final, lanza de nuevo la pregunta, esta vez omite el elemento divino explícitamente, pero lo deja claro de manera implícita:

Unde potest avidus captae leo parcere praede?

sed tamen esse tuus dicitur: ergo potest.

(Mart., 1, 14, 5-6)

espectáculos circenses, mismos que patrocinaba con gran pompa, cf. Suet., Dom., 4, 1: spectacula assidue magnifica et sumptuosa edidit [sc. Domiciano].

70 Por la construcción del verso en latín, parece claro que de los varios leones en la arena (los Caesarei leones aparecen en plural, v. 3), solo uno es el que agarró la liebre (esta juega in ore, en singular, v. 4).

${ }^{71}$ De manera similar funciona el Epigrama, 8, 53, aunque ahí se compara a Domiciano (de nuevo, a través del imponente león que está en la harena) con Hércules, y se involucra también el papel de Vespasiano y Tito divinizados (vv. 15-16). Cf. Watson-Watson 2003, pp. 179-180, 183-184.

72 El suceso con la liebre y los leones es caracterizado como miraculum, además de que el sustantivo auctor y el verbo adesse recalcan el carácter sagrado, cf. Walter 1996, pp. $66 \mathrm{~s} .$, y Citroni 1975, p. 39. 
¿De dónde puede un ávido león ser clemente con la capturada presa?

Pero, pues, se dice que [el león] es tuyo, ¡así que puede!

La potencia divina del emperador tiene la fuerza de invertir el orden natural de las cosas, e irradia, por así decir, de él para reflejarse en el león: el avidus leo se abstiene de herir (parcere, verbo que he traducido como "ser clemente", considerando el eco virgiliano de parcere subiectis... $)^{73}$ a su presa, una inocua liebre. El león se ha vuelto mitis, podríamos decir recordando el epigrama Spect., 10 (=12 SB), como mitis y clemens es el emperador mismo.

Después de variar las descripciones y alusiones del episodio en los demás epigramas de la serie, Marcial concluye con una composición más larga, el Epigrama, 104, divido en dos partes. Empieza con un crescendo de ejemplos que tienen el efecto de adynata sobre distintas escenas de animales amaestrados durante un espectáculo venático: leopardos amansados, tigres que obedecen al látigo, ciervos que se dejan conducir con el freno, osos de Numidia, igualmente refrenables, un salvaje jabalí que obedece a quien lo lleva, bisontes que tiran carros de combate como si fueran bueyes, incluso un elefante que baila obedeciendo a su domador (1-10). Una vez llegados al aparente culmen de la sumisión de la naturaleza al emperador, una inesperada respuesta a la pregunta retórica del v. 11 da un giro al epigrama (11-22): la "humilde" caza (venatus humiles, 13) de los leones a las liebres (ahora en plural), que lejos de ser "humilde" dejará en claro la grandeza del emperador, es la verdadera prueba de la magnanimidad imperial:

Quis spectacula non putet deorum?

haec transit tamen, ut minora, quisquis

venatus humiles videt leonum, quos velox leporum timor fatigat.

dimittunt, repetunt, amantque captos,

et securior est in ore praeda,

laxos cui dare perviosque rictus

gaudent et timidos tenere dentes, mollem frangere dum pudet rapinam,

stratis cum modo venerint iuvencis.

haec clementia non paratur arte,

sed norunt cuï serviant leones.

(Mart., 1, 104, 11-22)

¿Quién no consideraría que son espectáculos de los dioses?

Mas pasa de largo esto, como algo menor, quien

\footnotetext{
${ }^{73}$ Verg., Aen., 6, 853. Considérese también Mart., 1, 104, 21, infra. La clementia es el valor romano por antonomasia, al menos desde Julio César. Cf. Citroni 1975, p. 36. Para el motivo del magnus animus senecano (Sen., Clem., 1,5), en los pasajes que siguen, v. infra.
} 
ha visto la humilde caza de los leones:

los fatiga el veloz temor de las liebres.

Las sueltan, las vuelven a tomar, y capturadas, las cuidan;

y la presa está más segura en su boca.

Se alegran de tener a quien mostrarle su mandíbula abierta

y accesible, y detener, tímidos, los colmillos,

pues se avergüenzan de romper la suave presa,

aunque hayan apenas llegado de abatir unos novillos.

Esta clemencia no se prepara con entrenamiento,

sino que saben al servicio de quién están, los leones.

La clementia (21) que muestran los feroces felinos al no herir a las inofensivas liebres -e incluso mostrar su amor, cf. amare en v. 15- mientras poco antes habían despedazado a unos novillos (20), no se inculca con entrenamiento o esfuerzo humano (arte, 21), asegura Marcial; es la irrefutable prueba, una vez más, de que la imponente majestad y divinidad de Domiciano se refleja en los leones: ellos reconocen ${ }^{74}$ en él a su señor (v. 22); ellos representan su clementia. Con palabras clave como clementia, amare, non arte y servire, la voz del epigramatista deja en claro el mensaje panegírico: Domiciano es representado como clemens y lleno de amor incluso con los más débiles e indefensos, al mismo tiempo como dominus (los leones son sus servi). La propia naturaleza reconoce a su 'patrón' y esta lo imita al hacer que el mismo rey de los animales (el león había sido ya llamado dominus rexque en $1,60,5)$ muestre su sumisión espontáneamente, es decir: sin ars, como el elefante en Spect., 17 (= 20 SB), o como en Spect., 30 (= $33 \mathrm{SB})$, el mentir asociado al entrenamiento de las fieras es opuesto a la espontaneidad con que estas reconocen el poder del emperador (v. 7). Dicha sumisión se expresa con la imitación de los valores romanos por antonomasia (y muy senecanos), ${ }^{75}$ que caracterizan naturalmente aquí a Domiciano: clementia, amor y magnanimitas.

74 Citroni 1975, p. 320, subraya el reconocer activamente el dominio de Domiciano, más que un "magico estendersi della clementia dell'imperatore". Un pasaje en cierta medida paralelo se podría localizar en 4, 30: ahí son los peces que se hallan en el Baianus lacus, propiedad del emperador, quienes lo reconocen y salen a la superficie a tocar con la boca su mano (qui [sc. pisces] norunt dominum manumque lambunt, 2; v. infra el tratamiento que el lector puede encontrar sobre este pasaje en Juv., 4), o en el ya tratado Spect., 17 (= $20 \mathrm{SB}$ ).

75 Cf. Sen., Clem., 1, 5, 5: el magnus animus de un gobernante se manifiesta precisamente en la abstención de emplear la fuerza y la violencia. El ejemplo natural que proporciona Séneca es el del reino animal, en particular elefantes y leones: estos animales 'regios' muestran magnanimidad al no ensañarse con sus víctimas, sino a "sobrepasar lo que han abatido". Lo opuesto a esta 'clemencia' es la 'obstinación' típica de las bestias salvajes: ferarum ... quidem [est] praemordere et urguere proiectos. elephanti leonesque transeunt, quae inpulerunt; ignobilis bestiae pertinacia est. Cf. Wiener 2018, pp. 372 s. 
Otro retrato de la índole de Domiciano a través de una anécdota en la arena con un león se encuentra en un autor contemporáneo a Marcial, aunque de otro corte: Estacio. En el segundo libro de sus Silvae, una amplia colección de poesías de ocasión dedicadas a distintos patrones de la alta sociedad romana, publicada en torno al año 92/93, se halla una composición particular: la Silva, $2,5{ }^{76}$ Se trata de un breve poema sobre la muerte accidental de un león amansado (leo mansuetus, Stat., Silv., praef., 2, 17 s.) en la arena y la reacción que el emperador Domiciano, que estaba presente, tuvo al respecto.

Aunque el significado puntual de la silva no es del todo claro, y no tenemos elementos suficientes para contextualizarlo con mayor profundidad, ${ }^{77}$ el tema es sin duda novedoso. Recuerda mucho los epigramas de Marcial (llama la atención la brevedad de la composición estaciana, como si fuera casi epigramática) ${ }^{78}$ por la situación y el contenido.

La composición presenta una estructura general bipartita: Newlands la resume así: ${ }^{79}$ vv. 1-15: la lamentatio por la muerte del león; vv. 16-30 la consolatio al emperador. Van Dam, por otro lado, subraya la "mixed form" que caracteriza la composición, que une los topoi de laudatio, lamentatio, descriptio mortis y consolatio. Sugiere una estructura dividida en cuatro secciones: la laudatio/lamentatio (1-7); la lamentatio/descriptio mortis (8-15); la descriptio mortis/laudatio (16-23); finalmente, la consolatio (24-30). ${ }^{80}$

La obra empieza con una serie de preguntas retóricas que subrayan las cualidades del león (cf. el apóstrofe al león en el v. 7 como doctus, aludiendo a los trucos que 'aprendió': 1-6) y lamentan su muerte. Posteriormente se describen las tácticas de caza al león más practicadas y se contraponen a la muerte accidental del felino de la silva, sucedida cerca de su jaula en la arena (8-15). Sigue la escena donde los "compañeros" leones ven tristes al

\footnotetext{
${ }^{76}$ Sobre la relación de Estacio con sus ‘mecenas', cf. White 1975 y Nauta 2002. Sobre Stat., Silv., 2, 5, cf. Van Dam 1984, pp. 368 s., y Newlands 2011, pp. 192-202. El libro 2 de las Silvas se enfoca en la relación naturaleza-control humano, en el marco de una identidad cultural de la época flavia, como demuestra Newlands; cf. además Augoustakis 2007, p. 208. También destacan Cancik 1971; Krasser 2009, pp. 259-274; Nauta 2002, pp. 402-404, y Leberl 2004, p. 198.

${ }^{77}$ El poema no puede ser datado con precisión: cf. Van Dam 1984, pp. 371 s. Tampoco es posible saber cómo y por qué en particular murió el león. Para Newlands 2011, p. 193, incluso la presencia del emperador, escondido hasta el final de la composición "is enigmatic. The tone of 2.5 is thus hard to gauge".

${ }^{78}$ Cf. Stat., Silv., praef., 2, 15-16: Estacio se refiere a las Silvas 2, 3 y 2, 4 como libellos quasi epigrammatis loco scriptos. Para 2, 5, él ve necesaria eandem ... stili facilitatem, pues la poesía nació de manera casi inmediata tras los sucesos en el teatro. Cf. Van Dam 1984, pp. 368-369; Newlands 2011, p. 192. Aunque evidentemente la silva no es ningún epigrama, más bien se inscribe en subgénero, como anota Newlands (ibid.) del exitus illustrium virorum (Plin., Epist., 8, 12, 4), en la tradición de la consolatio (cf. Van Dam 1984, p. 369).

${ }^{79}$ Newlands 2011, p. 193.

${ }^{80}$ Van Dam 1984, p. 369. Sigo su texto latino a continuación.
} 
caído en la arena; a este se le compara con el soldado herido mortalmente en batalla, a quien sus compañeros rinden homenaje (16-23). Concluye la silva la consolación: la repentina muerte del león encuentra un gran consuelo (magna... subiti... solacia leti, 24$)$ en el hecho de haber sido una muerte valerosa como la de los gladiadores que el pueblo y el Senado admiran y, sobre todo, que el emperador se ha conmovido (24-30):

Quid tibi monstrata mansuescere profuit ira?

quid scelus humanasque animo dediscere caedes

imperiumque pati et domino parere minori?

quid, quod abire domo rursusque in claustra reverti

suetus et a capta iam sponte recedere praeda

insertasque manus laxo dimittere morsu?

occidis, altarum vastator docte ferarum,

non grege Massylo curvaque indagine clausus,

non formidato supra venabula saltu

incitus aut caeco foveae deceptus hiatu, sed victus fugiente fera. stat cardine aperto

infelix cavea, et clausas circum undique portas

hoc licuisse nefas placidi tumuere leones.

tum cunctis cecidere iubae, puduitque relatum

aspicere, et totas duxere in lumina frontes.

at non te primo fusum novus obruit ictu

ille pudor: mansere animi, virtusque cadenti

a media iam morte redit, nec protinus omnes

terga dedere minae. sicut sibi conscius alti

vulneris adversum moriens it miles in hostem

attollitque manum et ferro labente minatur,

sic piger ille gradu solitoque exutus honore

firmat hians oculos animamque hostemque requirit.

magna tamen subiti tecum solacia leti,

victe, feres, quod te maesti populusque patresque,

ceu notus caderes tristi gladiator harena,

ingemuere mori; magni quod Caesaris ora

inter tot Scythicas Libycasque, e litore Rheni

et Pharia de gente feras, quas perdere vile est,

unius amissi tetigit iactura leonis.

(Stat., Silv., 2, 5, 1-13 y 24-30)

¿De qué te sirvió domar la furia instintiva? ${ }^{81}$

¿De qué, borrar de tu ánimo la maldad y el asesinato;

\footnotetext{
${ }^{81}$ La propuesta de constrata, en vez de monstrata, que es adecuada para Augoustakis 2007, p. 220, convence menos: para la ira monstrata ("furia que mostrabas") en el sentido de "tu instinto salvaje”, cf. Van Dam 1984, pp. 372 s. Para la ira del león, cf. Lucr., 3, 296-298.
} 
soportar una potestad y obedecer a un patrón menos fuerte [que tú]?

¿De qué, que estés acostumbrado a salir y volver

de tu prisión y a separarte voluntariamente de la presa que has tomado, a soltar las manos que ponen [en tu boca] con una quijada floja? ${ }^{82}$

Te matan, experimentado destructor de grandes fieras:

No fuiste encerrado por una hueste de masilos [= africanos] en la curva red,

no fuiste incitado en aterrador salto sobre

las lanzas o engañado por la ciega apertura de una fosa;

sino que fuiste vencido por una fiera que huía. Queda con la puerta abierta

la infeliz jaula, y en torno, $\operatorname{tras}^{83}$ las puertas cerradas,

los callados leones se erizan ${ }^{84}$ porque ha sido posible tal sacrilegio.

Entonces a todos se les aplacaron las melenas, y les dio vergüenza ver

tu cuerpo que era arrastrado de vuelta, y fruncieron las ceñas hacia sus ojos.

Pero aquella vergüenza antes desconocida, no te abrumó,

aunque fuiste derrotado al primer golpe: permanecieron tus fuerzas, y el valor volvió

ya de la muerte profunda hacia ti que caíste, y no dieron la espalda

de inmediato todas tus amenazas: como el soldado que, consciente de

su grave herida, se dirige muriendo contra el enemigo,

levanta la mano y amenaza con la espada que cae,

así él, lento en su paso y despojado de su habitual dignidad

afirma su mirada rugiendo, y busca la fuerza y al enemigo.

No obstante, contigo tendrás un gran consuelo por la partida repentina,

aunque hayas sido vencido: que, triste, el pueblo y el senado,

como si hubieses caído cual célebre gladiador en la desolada arena,

llora tu muerte; que el rostro del gran César,

entre tantas fieras de Escitia, Libia, de la orilla del Rin

y de los pueblos del Faro, que sería insignificante perder,

se conmovió por la pérdida de un solo león que se ha ido.

La disposición del material y el objetivo de Estacio han sido muy estudiados en cuanto a esta composición. Destacan los momentos en que se divide y las características que resaltan cada uno de ellos, mismas que confluyen al final en la representación de Domiciano. Como en el caso del pius et supplex elephas de Marcial, Spect., 17 (=20 SB), el leo mansuetus aquí

\footnotetext{
${ }^{82}$ Precisamente el truco que había salido mal en Mart., Spect., 10 (= 12 SB), cf. supra.

${ }^{83}$ La lectura de circum undique no es clara, probablemente es resultado de corrupción textual. La imagen es que la jaula del león muerto queda abierta, mientras que las jaulas de los demás leones están cerradas, con ellos adentro, y están dispuestas alrededor de la jaula abierta: cf. Van Dam 1984, p. 381, quien, además, propone leer clausis ... portis.

${ }^{84}$ Como Van Dam 1984, ad loc. indica, la lectura de los manuscritos es timuere. Baehrens propone tumuere con base en la unión con ira (cf. Cic., Tusc., 3, 19: sapientis... animus... numquam tumet; Sen., Phoen., 352: tumet animus ira). El sentido de tumuere aquí parece indicar "erizarse" o "encresparse" por el horror que han visto los leones, situación que desencadena su rabia (cf. Newlands 2011, ad loc.).
} 
es símbolo de virtus, pues ha aprendido a controlarse, en particular refrena su natural ira. ${ }^{85} \mathrm{Su}$ heroicidad, evidenciada en el v. 7, cuando se le llama altarum vastator docte ferarum $^{86}$ es contrastada con la muerte accidental y fútil del león, resultado del golpe de un animal en fuga. Que Estacio no especifique con exactitud el accidente, obedece a dos factores, como convincentemente argumenta Krasser: ${ }^{87}$ por un lado, el público conocía bien el desarrollo de los hechos; por el otro, responde a una estrategia poética precisa, pues el poeta subraya el carácter accidental, evitando los detalles que vuelven todo menos heroico y se concentra en provocar un "efecto emocional" en el público. ${ }^{88} \mathrm{~A}$ esto obedecen, entonces, la descripción humanizada de los leones con ceño fruncido por la tristeza, y la heroica comparación de los últimos pasos del león ya herido con el soldado que está muriendo, pero sigue lleno de coraje y dignidad, o con el gladiador que cae en combate en la tristis harena ${ }^{89}$ El plano político es subrayado, como han notado varios estudiosos, sobre todo en los últimos versos: la mención del verbo ingeтиere para el pueblo y Senado de Roma, e inmediatamente después del "rostro del gran César" (magni Caesaris ora), que queda 'conmovido'90 por la pérdida del león, enmarca las referencias, no solo geográficas del imperio, ${ }^{91}$ sino sobre todo con la política de 'pacificación' domicianea: los Balcanes, el Norte de África, la frontera germánica y Egipto. ${ }^{92}$ La última imagen es

${ }^{85}$ Para la mansuetudo como virtud humana, puesta en relación con la clementia, cf. Caes., B Gall., 2, 14, 5; 31, 4, y Augoustakis 2007, p. 211, nn. 10 y 11.

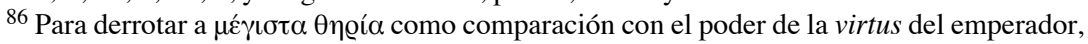
cf. Aymard 1951, p. 556.

${ }^{87}$ Krasser 2009, pp. 271-272.

${ }^{88}$ Krasser 2009, p. 271: "Statius takes all pains to push the bare facts aside as far as possible; instead, he concentrates on giving an account of the emotional effects felt by the spectators". Esto con el fin, como es evidente de proporcionar "a panegyrical interpretation of what had happened, preserving both the lion's and his owner's [i.d. del emperador] dignity". Un resumen de los posibles animales considerados para el combate contra el león los da Van Dam 1984, pp. 379 s.

${ }^{89}$ Augoustakis 2007,pp. 212 s. relaciona la caracterización del león aquí con la caracterización que Tácito hace de los catos, pueblo contra el cual Domiciano luchó precisamente durante los años 80 , periodo cuando probablemente habría nacido también la silva estaciana. Para la relación de esta descripción, vista también en los términos de una guerra civil, con la Tebaida del mismo Estacio, cf. Augoustakis 2007, pp. 216-219.

${ }^{90}$ Krasser 2009, p. 273, lo ve incluso como una señal para indicar el llanto, siguiendo el comentario de Van Dam 1984, p. 386. Newlands 2011, ad loc., es más cauta al notar que "tetigit does not necessarily imply 'wept' or denote a deep sorrow. Domitian was perhaps 'moved' by the animal's heroism and also by its loss as a valuable performer; perhaps too he was 'moved' by the implicit lesson of the 'king of the beasts' so treacherously bought low... tetigit draws attention to the inscrutability of Domitian's face".

${ }^{91}$ Cf. Van Dam 1984, p. 388.

92 Cf. Leberl 2004, pp. 198 s.; Nauta 2002, p. 404; Augoustakis 2007, pp. 219 s. Además, la caza como liberadora de 'plagas', es decir, de animales nocivos para la sociedad, como los 
la del emperador, siguiendo la interpretación de Krasser, ${ }^{93}$ quien, como en los epigramas de Marcial había manifestado su clementia, muestra aquí su misericordia a través de un espectáculo venatorio que, aunque haya salido mal, el poeta logra presentar a favor del emperador.

\section{b) Función crítica}

Newlands había notado que la aparición de Domiciano en la Silva, 2, 5, era "enigmatic", ${ }^{94}$ pues el emperador aparecía solo al final, casi escondido, esbozado indirectamente como "el rostro del gran César" y caracterizado por el vago verbo tango. Me parece que el efecto que esta puesta en escena crea contribuye a la representación de un emperador sensible y retirado, de hecho, intrigante. Juvenal presenta a Domiciano en la célebre cuarta sátira con una estrategia similar, aunque con el objetivo contrario al de Estacio: hacer una crítica indignada a su régimen, presentado como ridículo, autoritario y cruel..$^{95}$ Para tal objetivo, el satírico retoma puntos que habían sido usados hasta entonces de manera positiva en el discurso panegírico a Domiciano: el dominio sobre las fieras de la naturaleza, su índole tímida como expresión de su clementia y misericordia, finalmente su predilección por costosos espectáculos circenses para celebrar sus triunfos militares. Estos elementos se vuelven indicadores de la verdadera crueldad, injusticia y falta de libertad que imperó bajo su reinado. Para esto representa, como es característico en el autor, varias situaciones exageradas al ridículo.

En particular la Sátira cuarta se mofa del discurso panegírico que hemos encontrado hasta ahora en Marcial y Estacio, ${ }^{96}$ por ejemplo en lo relativo a la figura retirada de Domiciano, pero sobre todo en el tema de la sumisión de las grandes fieras de la naturaleza ante la magnanimidad del emperador.

La sátira está divida en dos grandes partes, separadas por un apóstrofe intermedio (en tono burlesco) a las musas: primero, se introduce al ridículo liberto enriquecido Crispino, ejemplo del mal gusto que parece insuperable

leones en África y Oriente, o los osos y jabalíes en Europa, es un motivo panegírico recurrente con fondo venatorio (cf. Claud. 24, 282-284).

${ }^{93}$ Krasser 2009, p. 272.

${ }^{94}$ Newlands 2011, p. 193.

95 Obviamente la sátira y todo el libro I fueron publicados años después de la caída de Domiciano. Para esta sátira, cf. sobre todo Braund 1996, pp. 236-275, y Santorelli 2012. Cf. también Flores Militello 2016. Para una cronología de la publicación del libro I de las Sátiras, cf. Nauta 2002, p. 442; cf. también Uden 2015, pp. 219-226. y Kelly 2018.

96 Particularmente 'antiestaciano' es el tono de la sátira en sí, que al parecer imita la composición perdida de Estacio De bello Germanico, que celebraría la victoria de Domiciano en Germania en 82/83. Cf. Stat., Theb., 1, 31-32. Cf. también Braund 1996, pp. 251 s.; Santorelli 2012, pp. 9-14, 135, 154; Flores Militello 2016, p. 351, n. 44, y p. 354. 
(1-33); después, tras una (des)invocación a las musas (34-36), demuestra cómo el mal gusto y el horror sí son superables en la medida en que la figura del emperador sobrepasa todas las cosas y personas (37-154). El episodio central es la pesca de un gigantesco rodaballo (rhombus) en las costas adriáticas (39) durante el reinado de Domiciano. Este tiene que ser donado al emperador, quien convoca, con carácter de urgente, a su consejo a su residencia albana. Juvenal describe la ridícula sesión deliberativa sobre cómo cocinar el pescado (74b-129): los grandes nobles de Roma son presentados como obesos, tontos, cobardes o sumisos. Finalmente, Domiciano, quien hasta ahora había asistido en silencio a la sesión (enigmático como en Estacio), entra en escena y pronuncia cuatro palabras, que se revelan igualmente ridículas: quidnam igitur censes? conciditur? ("Y entonces, ¿qué piensas? ¿Lo cortamos?", 130). Tras las últimas deliberaciones, se decide cocinarlo entero (131-149). La voz del satírico lamenta (sarcásticamente) que Domiciano no se hubiera dedicado más a tales nugae, pues en realidad pasó su mayor tiempo maquinando con sangrienta saevitia contra todos los órdenes sociales de Roma (150-154).

Ahora, en cuanto al discurso panegírico inverso, es decir, crítico, Juvenal retoma un discurso de Marcial que su lector conoce muy bien. Como todo el imperio está plagado de delatores, el pescador sabe que debe llevar su presa al ávido emperador (45-55): se le acusaría de inmediato por haber robado un pez que había huido de los vivaria Caesaris, ${ }^{97}$ pues "todo lo que es grande y bello en el mar entero, / pertenece al fisco, donde sea que esté nadando" (54 s.). En la escena donde el pescador da a Domiciano el pescado (64-69a) Juvenal se burla de la figura imperial en distintos niveles y retoma en clave irónica el discurso panegírico que se ha visto en Marcial:

itur ad Atriden. tum Picens "accipe” dixit

"priuatis maiora focis. genialis agatur

iste dies. propera stomachum laxare sagina

et tua seruatum consume in saecula rhombum.

ipse capi uoluit”. quid apertius? et tamen illi

surgebant cristae. nihil est quod credere de se

non possit cum laudatur dis aequa potestas.

(Juv., 4, 65-72)

Se va a donde está el Atrida. Entonces [el pescador] piceno dice: "toma algo demasiado grande para los fogones de los privados. Que se haga de fiesta este día. Apúrate a vaciar tu estómago de lo que hayas comido y consume este rodaballo que ha sido conservado para tus tiempos.

97 Cf. el Epigrama, 4, 30, de Marcial, donde los peces de las piscinas de Domiciano, en el Baianus lacus, de inmediato reconocen al César al verlo. 
Él mismo quiso ser atrapado". ¿Qué hay de más obvio? Y sin embargo a él se le paraba la cresta. No hay nada que no pueda creer de sí cuando se alaba su poder 'igual a los dioses'.

No solo se le compara con el orgulloso Agamenón, o se le pone al nivel del simple pescador que lo invita a "liberar su estómago"98 para poder comer el pescado "que ha sido conservado para tus tiempos", retomando, por ejemplo, la idea de los saecula dorados de un Nerón en la Égloga séptima de Calpurnio ${ }^{99}$ pero invirtiéndola en tono escatológico; sino que incluso el discurso panegírico del dominio sobre la naturaleza y la divinidad imperial, omnipresente en los epigramas de Marcial que he presentado, es retomado y desenmascarado como adulación pura: los peces de Mart., 4, 30, "que reconocen a su señor y le lamen la mano" (4) en cuanto lo ven; los leones de Mart., 1, 104, "que saben al servicio de quién están" (22), e incluso el pius et supplex elephas de Mart., Spect., 17 (= 20 SB), que "también percibe [la presencia de] nuestro dios" (4), todos son puestos aquí por Juvenal como una obvia (aperta) adulación de la que nadie podría dudar, a excepción del necio emperador a quien, como los orgullosos gallos "se le levanta la cresta" cada vez que escuchaba la alabanza de su "poder "igual a los dioses", recalca el satírico. Que para Juvenal esto es ridículo, resulta también evidente por el animal que usa: mientras los epigramas habían presentado animales regios (y provenientes de lugares de prestigio), como el león y el elefante, así como los animosos peces de las piscinas de la lujosa Bayas, Juvenal presenta un ominoso y horrible (cf. hoc monstrum, v. 45) pez del Adriático.

El tema venatorio vuelve, más adelante, para retomar la imagen de Domiciano como aficionado enfermo de los juegos circenses: entre los miembros del consilium Caesaris están los Acilii padre e hijo (94-104). A este último, agrega Juvenal, le esperaba una cruel muerte bajo las espadas de los emisarios de Domiciano (95-96). El elemento que subraya lo indignante de la circunstancia radica precisamente en la harena: dicho emperador habría obligado al joven Acilio, antes de mandarlo asesinar, a luchar como venator contra salvajes osos africanos (99-101) en la arena privada de la villa albana, sin ningún arma o protección en absoluto (nudus) ${ }^{100}$ o quizás solo alguna lanza (cf. el verbo figere):

\footnotetext{
98 Aunque la frase stomachum laxare sagina también se puede entender como "expandir tu estómago con la comida", es decir una torpe invitación a comer el pescado (cf. Braund 1996, ad loc.), me parece más atinada la lectura 'laxativa', como aún más torpe invitación a vaciar el estómago de comida sin valor (sagina) para comer el imponente pescado (cf. Santorelli 2012, ad loc.).

${ }^{99}$ La equiparación de Nerón y Domiciano, la había ya mostrado Juvenal en los vv. 37-38, al llamar al Flavius ultimus como calvus Nero. Cf. Charles 2002, pp. 19-21; Cordes 2017, p. 312.

${ }^{100}$ Para el sentido de nudus no como desnudo literalmente, sino cubierto de una pequeña tela en la cadera, como típicamente los pescadores o atletas en la época imperial (análogamente al griego $\gamma u \mu v o ́ s)$, cf. Courntey 1980, p. 179.
} 
proximus eiusdem properabat Acilius aeui

cum iunene indigno quem mors tam saeua maneret

et domini gladiis tam festinata; ...

profuit ergo nihil misero quod comminus ursos

figebat Numidas Albana nudus harena

uenator.

(Juv., 4, 94-96a y 99-101a)

Junto a él [sc. a otro miembro del consejo], se apresuraba Acilio, de la misma edad, con su muchacho, que no era digno de la muerte que le esperaba, tan cruel y tan prematura a causa de las espadas del tirano [sc. Domiciano]....

$$
\text { [...] }
$$

Entonces no le sirvió de nada al pobre el haber atravesado de cerca a los osos númidas [= africanos], cazador casi desnudo en la arena de la villa albana.

Por Suetonio, Dom., 19, sabemos que era célebre la manía de caza de Domiciano en su residencia en los montes Albanos: le divertía atravesar con flechas las cabezas de sus víctimas animales, para hacerles "crecer" cuernos (ut duobus ictibus quasi cornua efficeret). Suetonio también afirma que este emperador había mandado asesinar a varios ex cónsules, como a Acilio Glabrión (nuestro Acilio filius) quasi molitores rerum novarum, es decir como conspiradores (Suet., Dom., 10). Dion Casio $(67,14,3)$ narra la anécdota de cuando Acilio, mientras era cónsul, suscitó la envidia de Domiciano porque logró combatir sin heridas y con éxito contra un león, precisamente en la villa albana durante los Iuvenalia. Dicha envidia sería la responsable de llevarlo, pocos años después, a la condena a muerte "a causa de impiedad", por ser considerado "conspirador'101 "y porque luchó con fieras" (ötı xà̀

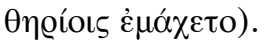

Independientemente de la historicidad del evento, el pasaje de Juvenal deja en claro dos cosas: primero, que el hecho de que un noble romano luche en la arena como venator (instigado por el propio emperador) antes de ser mandado matar, es considerado por el satírico como degradante, tanto para la víctima como para el victimario, pero sobre todo para Roma como Estado). ${ }^{102}$ Segundo, y más importante, que, al presentar a un cruel y sádico Domiciano aficionado al circo, invierte la asociación con la magnanimitas,

\footnotetext{
${ }^{101}$ Sobre las particularidades en torno al asesinato de Acilio Glabrión (¿referencia a su cristianismo?), cf. Courntey 1980, p. 218; Santorelli 2012, pp. 117 ss.; Flores Militello 2016, p. 359.

102 Para una posible crítica indirecta incluso a los tiempos de Trajano, cf. Santorelli 2012, aunque no me parece del todo verosímil. Es más presente, a mi parecer, la sensación de "atemporalidad" la que domina en los primeros libros de Juvenal, cf. Uden 2015, p. 12.
} 
clementia y misericordia que habían sido el Leitmotiv en las composiciones venatorias de Marcial y Estacio, incluso en Calpurnio hacia Nerón.

El tema venatorio termina su aparición poética durante el Imperio con un dejo ácido de crítica. Naturalmente, esto no refleja una verdadera caída de la apreciación real de los juegos circenses, sino al contrario, deja entrever una imagen donde la venatio se encuentra en su apogeo. ${ }^{103}$ Es más bien el poeta particular, como Juvenal, quien expresa una visión crítica de los espectáculos en general (en esto sigue sin duda la tradición estoica de Séneca). ${ }^{104}$ Cuando él se lamenta de que solo con "pan y circo" (Juv., 10, 78-81) se mantiene ocupado al pueblo, mientras el poder al mando se lanza en inerte picada a la decadencia por su egoísmo y avaricia, debe ser claro para el lector de hoy que esto obedece al hecho de que el poeta reconoce en los juegos circenses el potencial de explotación política que el poder ejerce y al que la poesía puede contribuir, en negativo y en positivo, de una manera contundente.

\section{RECAPITULACIÓN}

He expuesto cómo en la época imperial, sobre todo bajo Nerón y Domiciano, el tema de la venatio fue activamente empleado por poetas particulares para fines panegíricos hacia el emperador. Esto es, sin duda, un reflejo de la popularidad abrumadora que tales representaciones circenses tuvieron en la sociedad romana y de cómo el poder supo sacar provecho de ello. Pero al mismo tiempo permite observar en qué medida la poesía se sirve de acontecimientos socioculturales para transmitir un mensaje político definido. Es, quizás, un fenómeno paralelo al que puede observarse en otras representaciones artísticas de igual temática (arte musiva, numismática, relieves funerarios e incluso pinturas parietales). Sin embargo, la poesía tiene, por un lado, la ventaja de poder invertir el mensaje, como en el caso de Juvenal, y crear una visión negativa; por el otro, la particularidad de poder recurrir a una serie de alusiones de corte filosófico (en especial ético-estoico, como la clementia o la magnitudo animi a la manera de Séneca) y entrelazarlas con la construcción poética en sí en géneros distintos (epos, carmen bucolicum, epigramma, silva, satura) aunque similares, y sobre todo afines a un mensaje panegírico muy agudo.

A mi parecer, esto permite observar, en general, el papel relevante que juega la poesía en el discurso político; en particular, el rol que juega en ella la venatio.

103 Para la continuidad e intensificación también de la producción literaria de panegírica oficial tras la muerte de Domiciano, sobre todo bajo Trajano, cf. Coleman 2000.

${ }^{104}$ Sen., Epist., 7. 
Hasta qué punto esto es constatable también en la Antigüedad tardía, cuando el tema venatorio y la poesía (panegírica) volvieron a tener una importante presencia, queda como objeto para una futura investigación.

\section{BIBLIOGRAFÍA}

\section{Fuentes antiguas}

Claudi Aeliani De natura animalium libri xvi. varia historia, epistolae fragmenta, ed. Rudolf Hercher, Leipzig, B. G. Teubner, 1864 (reimp. 1971).

[C. IVliI CAesaris] Commentarii vol. III, ed. Alfred Klotz, Leipzig, B. G. Teubner, 1928 (reimp. Stuttgart, 1966).

C. IVli CAesaris Commentarii rerum gestarum. Vol. 1 Bellum Gallicum, ed. Otto Seel, Leipzig, B. G. Teubner, 1961.

Calpurnil siculi Eclogae, Maria Assunta Vinchesi, Firenze, Felice Le Monnier, 2014.

T. Calpurnio siculo, Ecloga VII, intr., ed. critica, trad. e comm. Lucia Di Salvo, Bologna, Pàtron, 1990.

Cassir Dionis cocceiani Historiarum Romanarum quae supersunt, ed. Ursul Philip Boissevain, Berlin, Weidmann, 1895-1931.

M. TVlli Ciceronis Epistulae ad Atticum. Vol. I. Libri I-VIII, ed. D. R. Shackleton Bailey, Stuttgart, B. G. Teubner, 1987.

M. TVLli Ciceronis Epistulae ad familiares. Libri I-XVI, ed. D. R. Shackleton Bailey, Stuttgart, B. G. Teubner, 1988.

M. TVlli Ciceronis Scripta quae mansuerunt omnia. Fasc. 44: Tusculanae disputationes, ed. Max Pohlenz, Berlin/New York, Walter de Gruyter, 1918 (reimp. 2008).

M. TVlli Ciceronis Scripta quae mansuerunt omnia. Fasc. 45: De natura deorum, ed. W. Ax, Berlin/New York, Walter de Gruyter, $1933^{3}$ (reimp. 2008).

M. TVlli Ciceronis De republica, de legibus, Cato Maior de senectute, Laelius de amicitia, ed. J. G. F. Powell, Oxford, Oxford University Press, 2006.

Clavdi Clavdiani Carmina, ed. John Barrie Hall, Leipzig, B. G. Teubner, 1985.

m. Cornelit Frontonis Epistulae, ed. Michael P. J. Van den Hout, Leipzig, B. G. Teubner, 1988.

Corpus Inscriptionum Latinarum [CIL], Berlin, Brandenburgische Akademie der Wissenschaften, 1853-.

Isocrate, Discours, Vol. 3., ed. G. Mathieu, Paris, Les Belles Lettres, 1924 (reimp. 1966).

M. anNei Lvcani De bello civili libri X, ed. D. R. Shackleton Bailey, Stuttgart, B. G. Teubner, $1997^{2}$.

TITVs LvCRetivs CARvs, De rerum natura libri VI, ed. Marcus Deufert, Berlin/Boston, Walter de Gruyter, 2019.

Marcus Aurelius, The Meditations of the Emperor Marcus Antoninus, Vol. 1: Text and Translation, ed. A. S. L. Farquharson, Oxford, Oxford University Press, 1944 (reimp. 1968). 
M. val. Martialis Epigrammata, ed. Wallace M. Lindsay, Oxford, Oxford University Press, $1929^{2}$.

M. VALERII MARTIALIS Epigrammaton liber. Introduzione e testo critico, Ugo Carratello, Roma, Cadmo, 1981.

M. valerit Martialis Epigrammata post W. Heraeum, ed. David R. Shackleton Bailey, Stuttgart, B. G. Teubner, 1990.

Oppianus apameensis, Cynegetica; Eutecnicus Sophistes, Paraphrasis metro soluta, ed. Manolis Papathomopoulos, München/Leipzig, K. G. Saur, 2003.

PS.-OpPIAn, Kynegetika, ed. Stephan Renker, Berlin/Boston, De Gruyter, 2020.

Ovid, Heroides, Amores, ed. Grant Showerman, G. P. Goold, Cambridge/London, Harvard University Press, 1977.

Ovid, Metamorphoses Vol. I-II, ed. Frank J. Miller, G. P. Goold, Cambridge/London, Harvard University Press, 1977-1984.

a. Persi flacci et d. ivni ivvenalis Saturae, ed. Wendell V. Clausen, Oxford, Oxford University Press, $1992^{2}$.

Plautus, Volumes I-V, ed. Wolfgang de Melo, Cambridge/London, Harvard University Press (LOEB Classical Library), 2011-2013.

C. Plinil Secvndi Naturalis historiae libri XXXVII, ed. Ludwig von Jan, Karl Mayhoff, Stuttgart, B. G. Teubner 1892-1909 (reimpresión 1967-2002).

C. Plini Caecili secvndi Epistularum libri decem, ed. Roger A. B. Mynors, Oxford, Oxford University Press, 1966.

Res Gestae. Imperatoris Caesaris Augusti Operum Fragmenta, ed. Enrica Malcovati, Roma, Edizioni Roma, $1962^{4}$.

L. AnNAei Senecae Ad Lucilium Epistulae Morales. Vols. I-II, ed. Leighton D. Reynolds, Oxford, Oxford University Press, 1965.

L. annaei Senecae Dialogorum libri duodecim, ed. Leighton D. Seneca Reynolds, Oxford, Oxford University Press, 1977.

L. Annaei Senecae Tragoediae, ed. Otto Zwierlein, Oxford, Oxford University Press, 1987.

L. annaei Senecae Opera quae supersunt. Vol. I, fasc. 2, ed. Carl Hosius, Leizpig, B. G. Teubner, $1914^{2}$.

P. PAPINI StATI Thebaidos libri XII, ed. D. E. Hill, Leiden, Brill, 1983.

Scriptores Historiae Augustae Vol. I, ed. Christa Samberger, Wolfgang Seyfarth, Ernst Hohl, Leipzig, B. G. Teubner, 1965.

Strabonis Geographica, ed. A. Meineke, Leipzig, B. G. Teubner, 1877 (reimp. 1969).

C. Svetoni tranqvilli De vita Caesarum libri VIII, ed. Robert A Kaster, Oxford, Oxford University Press, 2016.

CoRneli Taciti Opera minora, ed. J. G. C. Anderson Oxford, Oxford University Press, 1939.

P. CORNELII TACITI Libri ab excessu divi Augusti, ed. Erich Koestermann, Leipzig, B. G. Teubner, $1965^{5}$.

Titi Livi Ab Urbe condita vol. I-IV, ed. Robert Seymour Conway, Carl Flamstead Walters, Oxford, Oxford University Press, 1914-1935.

P. Vergili maronis Opera, ed. Roger A. B. Mynors, Oxford, Oxford University Press, 1969. 
Xenophontis Opera omnia, vol. 3, ed. Edgar C. Marchant, Oxford, Oxford University Press, 1961.

\section{Fuentes modernas}

AA.VV., Thesaurus Linguae Latinae [TLL], München, 1900-.

Andreae, Maria Theresia, "Tiermegalographien in pompejanischen Gärten. Die sogenannten Paradeisos-Darstellungen”, Rivista di Studi Pompeiani, 4, 1990, pp. 45-124.

Augoustakis, Antony, “Unius amissi leonis: Taming the Lion and Caesar's Tears (Silvae 2.5)", Arethusa, 40, 2007, pp. 207-221.

Aymard, Jacques, Essai sur les Chasses Romaines des origins à la fin du siècle des Antonins (Cynegetica), Paris, E. de Boccard, 1951.

Beagon, Mary, Roman Nature. The Thought of Pliny the Elder, Oxford, Oxford University Press, 1992.

Braund, Susana M., Juvenal. Satires Book I, Cambridge, Cambridge University Press, 1996.

CAmeron, Alan, "Claudian revisited", en Franca Ela Consolino (ed.), Letteratura e propaganda nell'occidente latino da Augusto ai Regni romanobarbarici, Roma, L'Erma di Bretschneider, 2000.

CANCIK, Hubert, "Amphitheater. Zum Problem der ,Gesamtinterpretation" am Beispiel von Statius, Silve II 5: Leo Mansuetus”, Der Altsprachliche Unterricht, 14, 1971, pp. 66-81.

Charles, Michael, “Calvus Nero: Domitian and the Mechanics of Predecessor Denigration", Acta Classica, 45, 2002, pp. 19-49.

Citroni, Mario, M. Valerii Martialis Epigrammaton Liber Primus, Firenze, La Nuova Italia, 1975.

Coleman, Kathleen M., "Latin Literature after AD 96: Change or Continuity?", American Journal of Ancient History, 15, 2000, pp. 19-39.

Coleman, Kathleen, M. M. Valerii Martialis Liber Spectaculorum, Oxford, Oxford University Press, 2006.

Cordes, Lisa, Kaiser und Tyrann. Die Kodierung und Umkodierung der Herrscherrepräsentation Neros und Domitians, Berlin/Boston, De Gruyter, 2017.

Courntey, Edward, A Commentary on the Satires of Juvenal, London, The Athlone Press, 1980.

van Dam, Harm-Jan, P. Papinius Statius, Silvae Book II. A Commentary, Leiden, Brill, 1984.

Dunbabin, Katherine M. D., The Mosaics of Roman North Africa. Studies in Iconography and Patronage, Oxford, Oxford University Press, 1978.

Dunbabin, Katherine M. D., Mosaics of the Greek and Roman World, Cambridge, Cambridge University Press, 1999.

Dunbabin, Katherine M. D., Theater and Spectacle in the Art of the Roman Empire, Ithaca/London, Cornell University Press, 2016.

Epplett, Chris, "Roman Beast Hunts", in Paul Christesen and Donald G. Kyle 
(eds.), A Companion to Sport and Spectacle in Greek and Roman Antiquity, Chichester, Wiley Blackwell, 2014, pp. 505-519.

Flores Militello, Vicente, “Juvenals 4. Satire: Die Anordnung des Bösen”, Gymnasium, 123, 2016, pp. 341-373.

Flores Militello, Vicente, Tali dignus amico. Die Darstellung des patronus-cliensVerhältnisses bei Horaz, Martial und Juvenal, Tübingen, Narr Francke Attempo, 2019.

Formicola, Crescenzo, Il Cynegeticon di Grattio, Bologna, Pàtron, 1988.

GARZYA, Antonio, "Sull'autore e il titolo del perduto poema 'Sull'aucupio' attribuito ad Oppiano", Giornale Italiano di Filologia, 10, 1957, pp. 156-160.

GNILKA, Christian, "Die Tiere im hölzernen Amphitheater Neros. Wort- und Versinterpolation bei Calpurnius Siculus", Wiener Studien, 8, 1974, pp. 124-153.

Green, Steven J., Grattius. Hunting an Augustan Poet, Oxford, Oxford University Press, 2018.

Holzberg, Niklas, Martial, Heidelberg, Carl Winter, 1988.

Howell, Peter, A Commentary on Book One of the Epigrams of Martial, London, The Athlone Press, 1980.

JAKOBI, Rainer, Nemesian, Cynegetika, Berlin/Boston, De Gruyter 2014.

Jones, Brian W., The Emperor Domitian, London/New York, Routledge, 2002.

Karakasis, Evangelos, T. Calpurnius Siculus: A Pastoral Poet in Neronian Rome, Berlin/Boston, De Gruyter, 2016.

Keller, Otto, Die antike Tierwelt. Erster Band: Saugetiere, Leipzig, Wilhelm Engelmann, 1909.

Kelly, Gavin, "From Martial to Juvenal (Epigrams 12.18)", in Alice König and Christopher Whitton, Roman Literature under Nerva, Trajan and Hadrian: Literary Interactions, $A D$ 96-138, Cambridge, Cambridge University Press, 2018, pp. 160-178.

KNOCHE, Ulrich, Untersuchungen zur Entstehung und Entwicklung eines römischen Wertgedankens, Leipzig, Dieterich'sche Verlagsbuchhandlung (Philologus Supplementband, 27, 3), 1935.

KorZENIEwSKI, Dietmar, "Zur ersten und siebten Ekloge des Calpurnius Siculus", Museum Helveticum, 33, 1976, pp. 248-253.

Krasser, Helmut, "Statius and the Weeping Emperor (Silv. 2.5): Tears as a Means of Communication in the Amphitheatre", in Thorsten Fögen (ed.), Tears in the Graeco-Roman World, Berlin/Boston, De Gruyter, 2009, pp. 253-275.

LEACH, Eleabir W., "Corydon Revisited: An Interpretation of the Political Eclogues of Calpurnius Siculus", Ramus, 2, 1973, pp. 53-97.

Leberl, Jens, Domitian und die Dichter. Poesie als Medium der Herrschaftsdarstellung, Göttingen, Vandenhoeck \& Ruprecht, 2004.

Lewis, C. T., and C. Short (eds.), [L\&S], A Latin Dictionary, Oxford, Clarendon Press, 1975.

NautA, Ruurd R., Poetry for Patrons, Leiden/Boston/Köln, Brill, 2002.

Newlands, Carole E., Statius Silvae Book II, Cambridge, Cambridge University Press, 2011.

Ovadiah, Asher, and Sonia Mucznik, "Classical Heritage and Anti-Classical Trends in the Mosaic Pavement of Lydda (Lod)", Assaph. Studies in Art History, 3, 1998, pp. 1-16. 
Puk, Alexander, Das römische Spielewesen in der Spätantike, Berlin/Boston, De Gruyter, 2014.

REA, Rossella, "Gli animali per la venatio: Cattura, trasporto, custodia", en Adriano La Regina (ed.), Sangue e Arena, Milano, Electa, 2001, pp. 245-275.

Ryser, Gabriela, "The Hidden Model? Influences from Oppian in Claudian's Latin Oeuvre", Hermes, 143, 2015, pp. 472-490.

SAntorelli, Biagio, Giovenale, Satira IV: Introduzione, traduzione e commento, Berlin/Boston, De Gruyter, 2012.

SCHINDleR, Claudia, Per carmina laudes, Untersuchungen zur spätantiken Verspanegyrik von Claudian bis Coripp, Berlin/New York, De Gruyter, 2009.

SCHNEIDER, Horst, "Thekla und die Robben", Vigiliae Christianae, 55, 2001, pp. 45-57.

Schulz, Verena, Deconstructing Imperial Representation: Tacitus, Cassius Dio, and Suetonius on Nero and Domitian, Leiden, Brill, 2019.

Silva Sánchez, Tomás, Sobre el texto de los Cynegetica de Opiano de Apamea, Cádiz, Universidad de Cádiz, 2002.

Townend, Gavin B., "Calpurnius Siculus and the Munus Neronis", The Journal of Roman Studies, 70, 1980, pp. 166-174.

Toynbee, Jocelyn M. C., Animals in the Roman Art and Life, London/Southampton, Thames and Hudson, 1973 (reimp. 2013).

Uden, James, The Invisible Satirist: Juvenal and Second-Century Rome, Oxford, Oxford University Press, 2015.

Verdière, Raoul, Gratti Cynegeticon libri I quae supersunt, Leiden, E. J. Brill, 1964.

VInCHESI, Maria Assunta, Calpurnio Siculo. Ecloghe, Milano, Rizzoli, $2017^{7}$.

Walter, Uwe, M. Valerius Martialis. Epigramme, Paderborn/Wien/München/Zürich, Ferdinand Schöningh, 1996.

Watson, Lindsay, and Patricia Waston, Martial. Selected Epigrams, Cambridge, Cambridge University Press, 2003.

WeInReich, Otto, Studien zu Martial, Stuttgart, W. Kohlhammer, 1928.

White, Peter, "The Friends of Martial, Statius, and Pliny, and the Dispersal of Patronage", Harvard Studies in Classical Philology, 79, 1975, pp. 265-300.

Wiedemann, Thomas, Emperors and Gladiators, London/New York, Routledge, 1992.

WIENER, Claudia, "Stoa ohne stoische Terminologie? Senecas Vermittlungsstrategien”, in Gernot M. Müller/ Fosca M. Zini (eds.), Philosophie in Rom - Römische Philosophie? Kultur-, literatur- und philosophiegeschichtliche Perspektiven, Berlin/Boston, De Gruyter, 2018, pp. 349-384.

$$
* * *
$$

Vicente Flores Militello es licenciado en Letras Clásicas por la Universidad Nacional Autónoma de México (2011), en 2014 obtuvo la maestría (Magister Artium) en Filología Latina y Griega, en la Universidad de Múnich, Alemania (LMU München). En 2018 concluyó el doctorado en Filología Latina en la misma institución, con una tesis sobre la representación patronus-cliens en Horacio, Marcial y Juvenal 
(publicada en Alemania, Tubinga 2019). Desde 2019 es investigador de tiempo completo en el Instituto de Investigaciones Filológicas de la UNAM, con un proyecto sobre la épica panegírica tardo antigua, en particular el De consulatu Stilichonis de Claudio Claudiano. Ha publicado artículos académicos en revistas internacionales, así como traducciones al castellano de textos latinos y neolatinos. 